\title{
Evaluation of Global Satellite Mapping of Precipitation Project Daily Precipitation Estimates over the Chinese Mainland
}

\author{
Zhuoqi Chen, ${ }^{1}$ Yaxin Qin, ${ }^{1}$ Yan Shen, ${ }^{2}$ and Shupeng Zhang ${ }^{1}$ \\ ${ }^{1}$ State Key Laboratory of Remote Sensing Science, and College of Global Change and Earth System Science, Beijing Normal University, \\ Beijing 100875, China \\ ${ }^{2}$ National Meteorological Information Center, China Meteorological Administration, Beijing 100081, China
}

Correspondence should be addressed to Yan Shen; sheny@cma.gov.cn

Received 29 July 2015; Revised 30 October 2015; Accepted 1 November 2015

Academic Editor: Stefania Bonafoni

Copyright ( 92016 Zhuoqi Chen et al. This is an open access article distributed under the Creative Commons Attribution License, which permits unrestricted use, distribution, and reproduction in any medium, provided the original work is properly cited.

\begin{abstract}
Two versions of Global Satellite Mapping of Precipitation (GSMaP) products (GSMaP-V4 and GSMaP-V5) are validated both in a single grid scale and in contiguous China by comparing to gauge-based rainfall analysis dataset. GSMaP products can capture spatial patterns and magnitude of rainfall in daily mean precipitation. They perform better in summer than in winter over the Chinese Mainland. They also have better estimation over the southeast than over the northwest of the Chinese Mainland. An apparent system underestimate is detected in both GSMaP products. The underestimation existing in the GSMaP-V4 has been largely improved in GSMaP-V5. The impacts of snow cover and vegetation fraction are also investigated. The result indicates that snow cover deeply impacts the POD and FAR of GSMaP products. NDVI may result in overestimated precipitation in sparse vegetation regions. These results implicate that it is useful to use some auxiliary data from other sensors (e.g., MODIS) to improve the quality of precipitation product.
\end{abstract}

\section{Introduction}

Over the past decade, satellite meteorology has made great contributions to improving the understanding of the global water cycle and its effects on the large-scale dynamics of general atmospheric circulation. Several global or regional precipitation products, based on satellite observations, are used extensively in hydrology and meteorology applications $[1,2]$. These precipitation estimates include TRMM-TMPA, PERSIANN, CMORPH, and GSMaP [3-6]. These products combine precipitation information from multiple sensors (e.g., passive microwave (PMW) sensors and infrared (IR) radiometers) and multiple algorithms [7-11] to produce estimates of rainfall over the globe at a spatial resolution of $0.25^{\circ}$ latitude/longitude (or finer) and 3-hour temporal resolution (or less). Because these products are constructed from satellite data, they supply crucial rainfall information over the oceans and parts of the land where rain gauges are very sparse or nonexistent.

The validation of precipitation estimates made from satellite data is essential for assessing the skill of the estimation algorithms, providing users with constraints on the accuracy of data, and providing feedback to algorithm developers so that they can improve their methods. To understand the strengths and weaknesses of global rainfall products retrieved from remote sensing data, the International Precipitation Working Group (IPWG) established a program for validation of daily rainfall against rainfall measurements from rain gauges and radars [12]. Furthermore, such satellite precipitation datasets have been extensively evaluated all over the world in recent years [13-17].

The Global Satellite Mapping of Precipitation (GSMaP) is a set of new high-resolution precipitation estimates based on blending PMW and IR data. PMW data are used to estimate rain rate $[6,8,10]$. A morphing technique is used to calculate 
the moving vector of the cloud and propagate the rainy area during two pieces of the IR images [18]. A Kalman filter is applied to the rainfall rate after propagation along with the moving vector to update the rate [19]. The rain/no-rain classification scheme plays a key role in this project [20,21].

To facilitate GSMaP's application and assess its improvement over previous algorithms, it is crucial to quantify and document its error characteristics. Many evaluations and validations about the GSMaP product have been made in recent years. Kubota et al. [6] assessed the accuracy of GSMaP_MWR (MWR means microwave radiometer), a subset of GSMaP which combines with rainfall estimates derived from microwave radiometer over the ocean and the land from $15^{\circ} \mathrm{N}$ to $15^{\circ} \mathrm{S}$, and reported that (a) correlation coefficient of GSMaP is high over the ocean and relatively low over the land surface and (b) it is also higher in summer than in winter. They [14] also evaluated GSMaP 3-hourly and at $0.25^{\circ}$ around Japan by comparing GSMaP with a gauge-calibrated ground radar dataset. Tian et al. [22] indicated that GSMaP does well in capturing the spatial patterns of precipitation, especially in summer, over the United States. However, it tends to underestimate in winter and overestimate in summer. The GSMaP precipitation estimates have also been evaluated over Colombia by using a station network composed of 600 rain gauges [13].

Although the GSMaP product has been verified in many parts of the world, it rarely was evaluated over China. One exception is that of Qin et al. [23], who evaluated four highresolution satellite-based precipitation products $(\mathrm{CMORPH}$, TRMM, TRMM3B42, and GSMaP) using a gauge-based precipitation analysis over China. Other similar validation studies were limited to the specific regions/basins in China $[24,25]$. However, the old version GSMaP product (version 4.8.4, hereafter called GSMaP-V4) released in 2007 was used in their studies. In particular, the latest GSMaP product (version 5.2.2.2, hereafter called GSMaP-V5) was released in 2012. There are many improvements that have been done including ingesting more input data (e.g., SSMIS and AMUSA data), improving microwave imager algorithm, and developing orographic rainfall correction method, among others $[26,27]$. To identify the improvements and document error characteristics of the new GSMaP-V5, it is worth validating and comparing these two versions of GSMaP products. Furthermore, many previous studies have shown that errors in satellite-based precipitation estimates are partly related to complex topography and underlying surface types [28, 29]. Therefore, it is necessary to investigate error characteristics in detail for GSMaP over the Chinese Mainland with complex topography and various underlying surface types.

This study aims to (1) evaluate GSMaP products over the Chinese Mainland by using gauge-based rainfall analysis and (2) explore the error characteristics of GSMaP over regions with complex topography and various underlying surface types. This paper consists of five parts: Section 1 is the introduction; Section 2 describes the precipitation analysis dataset, GSMaP products, and evaluation statistics; Section 3 documents evaluation results; comparisons with previous studies were discussed in Section 4; and Section 5 presents the conclusions.

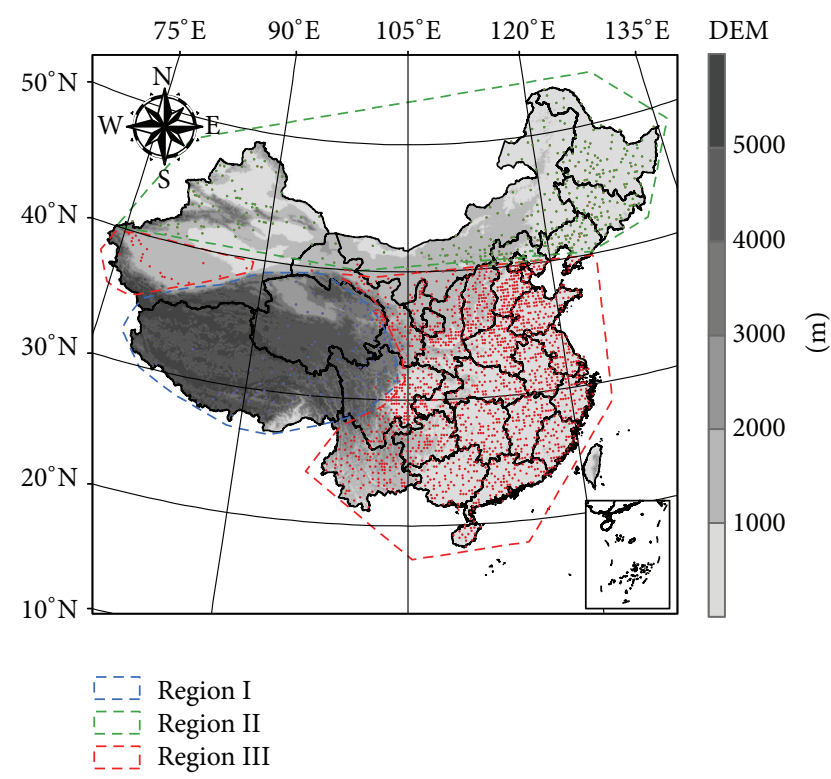

FIgURE 1: Distribution of grid boxes that contain at least one rain gauge and DEM. Blue points represent gauges located at high altitude regions (Region I) with elevation above $3000 \mathrm{~m}$. Green points represent gauges located at north of $40^{\circ}$ (Region II). Red points represent gauges located at lowland and low latitude regions (Region III).

\section{Material and Methods}

2.1. Gauge-Based Rainfall Analysis. Data for the gauge-based rainfall analysis were obtained by the National Meteorological Information Center of China Meteorological Administration (hereafter called CMA-GRA) [30, 31]. These data were provided based on a gauge network that consists of more than 2000 automatic weather stations (Figure 1). Daily CMAGRA was produced with $0.25^{\circ}$ resolution. The algorithm which is used to define the analyzed daily precipitation fields over China is an adaptation of the objective technique [32], which was developed originally for the construction of daily precipitation analysis over East Asia. First, the analyzed fields of daily precipitation climatology are computed by interpolating the station climatology over a 30 -year period from 1971 to 2000 [33]. These daily climatology fields are then adjusted by the Parameter-Elevation Regression on Independent Slopes Model (PRISM) monthly precipitation climatology of Daly et al. [34] to correct the bias caused by orographic effects. Gridded fields of daily precipitation are created by interpolating the corresponding station values using the optimal interpolation (OI) method. This dataset was successfully used to validate high-resolution satellitebased precipitation estimates both at single grid scale and over contiguous China [23,30]. In single grid scale, the grid contains at least one gauge that is used to evaluate the corresponding grid in GSMaP data for the period from 2003 to 2006. Then, the spatial distribution of error is shown over contiguous China by comparing every grid of the analysis data with the satellite estimates. 
2.2. Satellite Data. The GSMaP project $[6,8,19,35]$ is supported by Japan Science and Technology Agency (JST) and Japan Aerospace Exploration Agency (JAXA). It incorporates both passive microwave (PMW) and infrared (IR) sensors data from satellite to map global precipitation at high temporal and spatial resolution. In this study, GSMaP's surface rainfall products called "GSMaP_MVK+ version 4.8.4" and “GSMAP MVK version 5.2.2.2” were evaluated. They offer hourly precipitation estimates on $0.1^{\circ}$ latitude/longitude grid over the globe $\left(60^{\circ} \mathrm{S}\right.$ to $\left.60^{\circ} \mathrm{N}\right)$ from 2003 to 2006 . We chose the data of the entire 4-year period for this study, and all the datasets were evaluated and compared at a resolution of $0.25^{\circ}$ with daily accumulation.

Terra satellite was launched with a complement of five instruments including the Moderate Resolution Imaging Spectroradiometer (MODIS). Many geophysical products are derived from MODIS data including global snow cover [36] and normalized difference vegetation Index (NDVI, MODIS, 1999) products. These products have been available through Distributed Active Archive Center (DAAC) since September 13, 2000. In order to explore the error characteristics of GSMaP over regions with various underlying surface types, monthly snow cover fraction and NDVI with $0.05^{\circ}$ resolution derived from MODIS were collected.

2.3. Validation Statistics. Standard validation statistics are used to evaluate the GSMaP satellite products. The description of these statistics has been given in many references [37]. The formulas and a brief description of these statistics are provided here for the convenience of readers. Two kinds of statistics are usually used to verify satellite precipitation data. One is continuous verification statistics and the other is categorical verification statistics. Continuous verification statistics measure the accuracy of a continuous variable such as rain quantity or intensity. Categorical verification statistics measure the correspondence between the estimated and observed occurrences of events. The continuous verification statistics used to validate GSMaP in this study are mean error (ME), root mean square error (RMSE), and correlation coefficients (CCs). The formulas for these statistics are as follows:

$$
\begin{aligned}
\mathrm{ME} & =\frac{1}{N} \sum_{i=1}^{N}\left(Y_{i}-O_{i}\right), \\
\mathrm{RMSE} & =\sqrt{\frac{1}{N} \sum_{i=1}^{N}\left(Y_{i}-O_{i}\right)^{2},} \\
\mathrm{CC} & =\frac{\sum_{i=1}^{N}\left(Y_{i}-\bar{Y}\right)\left(O_{i}-\bar{O}\right)}{\sqrt{\sum_{i=1}^{N}\left(Y_{i}-\bar{Y}\right)^{2} \sqrt{\sum_{i=1}^{N}\left(O_{i}-\bar{O}\right)^{2}}}},
\end{aligned}
$$

where $Y_{i}$ is the estimated value at a point or grid box $i, O_{i}$ is the observed value, and $N$ is the number of samples.

The categorical verification statistics used to validate GSMaP in this study are probability of detection (POD)
TABLE 1: Contingency table for comparing gauge-based analysis and satellite estimates. The threshold used for rain/no-rain discrimination is $1.0 \mathrm{~mm} /$ day.

\begin{tabular}{lcc}
\hline & Gauge $\geq$ threshold & Gauge $<$ threshold \\
\hline Satellite $\geq$ threshold & Hits & False alarms \\
Satellite $<$ threshold & Misses & Correct negatives \\
\hline
\end{tabular}

and false-alarm ratio (FAR). They can be calculated by the following equations:

$$
\begin{aligned}
\text { POD } & =\frac{\text { hits }}{\text { hits }+ \text { misses }}, \\
\text { FAR } & =\frac{\text { false alarms }}{\text { hits }+ \text { false alarms }},
\end{aligned}
$$

in which hits and misses mean whether the satellite estimate precipitation detected ground observations; the contingency table for categorical verification statistics and the detailed definition are shown in Table 1 . In this study, $1 \mathrm{~mm} /$ day is used as the rain/no-rain threshold to improve the effectiveness of our validation.

2.4. Validation Regions. Validation statistics are computed for the whole country as well as for three separate regions (refer to Figure 1) as follows.

(1) Region I: Qinghai-Tibet Plateau. It consists of all areas with elevations that are above $3000 \mathrm{~m}$. Grids contain at least one gauge located in this region with complex topography and large area snow cover, marked in blue in Figure 1.

(2) Region II: Northern Areas, North of $40^{\circ} \mathrm{N}$. It includes arid and semiarid regions with mean annual rainfall below $800 \mathrm{~mm}$. Grids contain at least one gauge located in this region, marked in green in Figure 1. Since coverage of TRMM satellite is limited from $38^{\circ} \mathrm{N}$ to $38^{\circ} \mathrm{S}$, precipitation radar data are not available for GSMaP products. Therefore, it is possible to investigate performance of GSMaP when precipitation radar data are not available.

(3) Region III: The Southern Coastal Region. It is the wettest part of China and has mean annual rainfall of up to $3000 \mathrm{~mm}$. Grids contain at least one gauge located in this region, marked in red in Figure 1. Because dense vegetation covers are detected in this region, we try to identify errors in GSMaP induced by underlying surface conditions.

\section{Results}

3.1. An Overview of GSMaP's Performance over the Chinese Mainland. Gauge-based rainfall analysis data and GSMaP precipitation estimates were used to calculate statistics described in Section 2. The statistics are shown in Table 2. ME indicates that the GSMaP product underestimates precipitation by about $0.53 \mathrm{~mm} /$ day for GSMaP-V4 and $0.31 \mathrm{~mm} /$ day for GSMaP-V5. The underestimation existing in the GSMaPV4 has been largely improved in GSMaP-V5. RMSE increases 


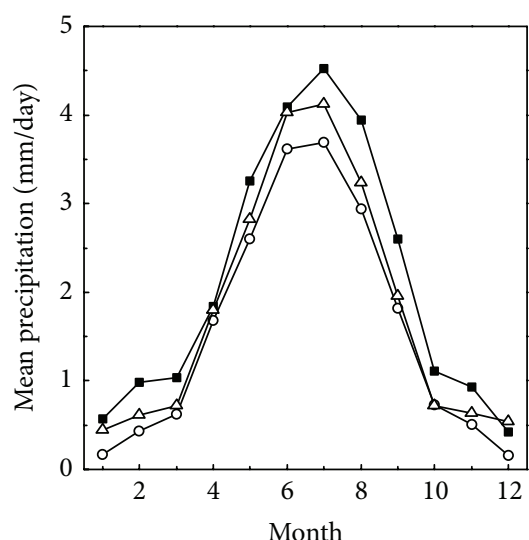

$-\mathrm{C}$ CMA-GRA $\triangle$ GSMaP-V5
$-\mathrm{-}$ GSMaP-V4

(a)

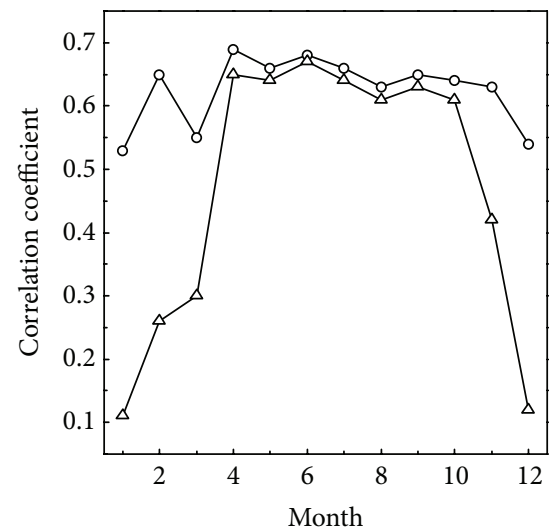

-O- GSMaP-V4

$-\triangle$ GSMaP-V5

(d)

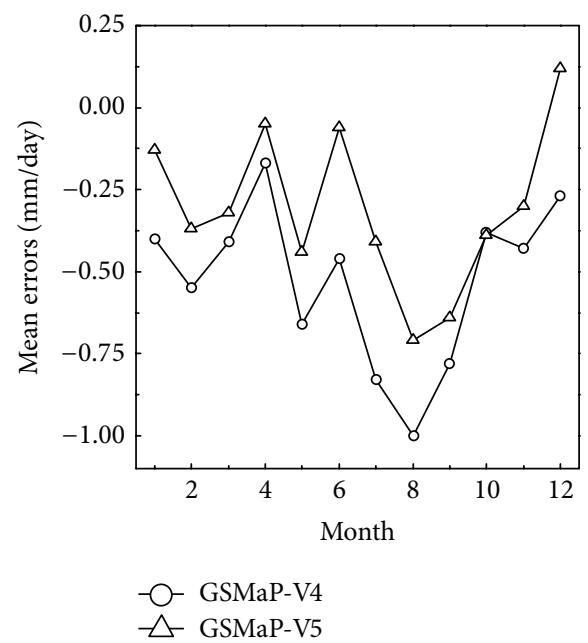

(b)

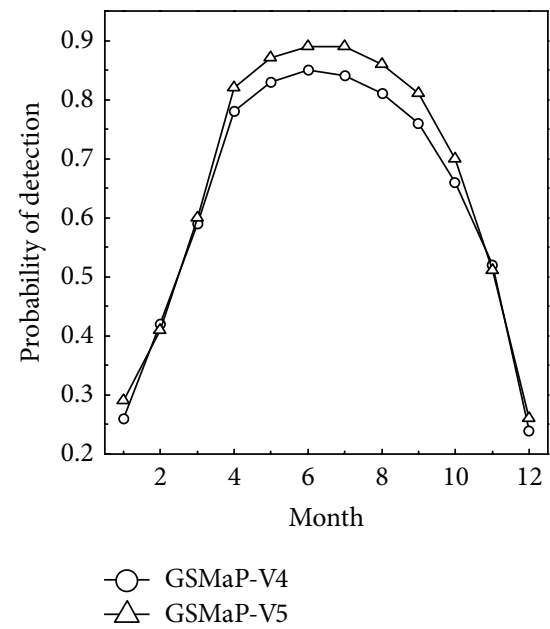

(e)

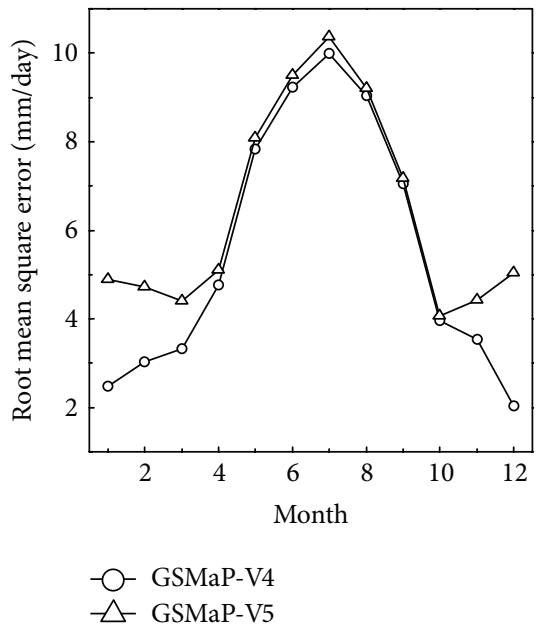

(c)

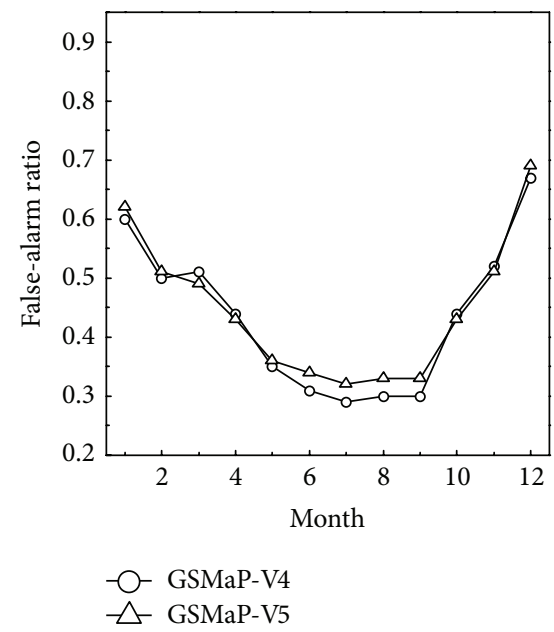

(f)

FIGURE 2: Seasonal variations of validation statistics of GSMaP products. (a) Mean precipitation, (b) mean errors, (c) root mean square error, (d) correlation coefficients, (e) probability of detection, and (f) false-alarm ratio.

TABLE 2: Validation statistics comparing the performances of GSMaP rainfall estimates over the Chinese Mainland from 2003 to 2006.

\begin{tabular}{lccccc}
\hline & ME (mm/day) & RMSE (mm/day) & CC & POD & FAR \\
\hline GSMaP-V4 & -0.53 & 6.21 & 0.66 & 0.70 & 0.38 \\
GSMaP-V5 & -0.31 & 6.80 & 0.60 & 0.73 & 0.40 \\
\hline
\end{tabular}

from $6.21 \mathrm{~mm} /$ day to $6.80 \mathrm{~mm} /$ day. CC is reduced slightly from 0.66 to 0.60 . POD is also slightly improved from 0.70 to 0.73 , while FAR is enhanced from 0.38 to 0.40 .

Seasonal variations of the validation statistics are shown in Figure 2. GSMaP-V4 and GSMaP-V5 perform reasonably well in capturing the seasonal variations of precipitation (Figure 2(a)). Both of these products show high precipitation in summer [June-August (JJA)] and low precipitation in winter [December-February (DJF)]. All GSMaP products underestimate precipitation all year round over the Chinese Mainland. About 50\% underestimation in winter and
$15 \%$ underestimation in summer are found in GSMaP-V4. GSMaP-V5 partly corrects the biases in GSMaP-V4 in winter and summer. However, performances in transition season are slightly improved in GSMaP-V5 (Figure 2(a)). Seasonal variations of $\mathrm{ME}$ also indicate that both products underestimate precipitation all year round (Figure 2(b)). GSMaP-V5 illustrates smaller negative biases than GSMaP-V4. Compared to GSMaP-V4, monthly RMSEs with GSMaP-V5 are slightly increased in summer and significantly increased in winter (Figure 2(c)). The monthly CCs of GSMaP-V4 are around 0.6 each month. The CC value of GSMaP can almost reach 0.7 in summer and falls down to 0.5 in winter. GSMaPV5 shows that monthly CCs are dramatically decreased in winter (Figure 2(d)). Although biases of GSMaP-V4 are partly corrected by GSMaP-V5, RMSE and CC indicate that performance of GSMaP-V5 is worse than GSMaP-V4's performance in winter. POD and FAR have significant seasonal variation in all datasets. In winter, the lowest POD is only $20 \%$, whereas the highest POD reaches nearly $90 \%$ in summer 
time (Figure 2(e)). In contrast with POD, the highest FAR is in winter and the lowest FAR is in summer (Figure 2(f)). POD and FAR scores of GSMaP-V5 are similar to GSMaPV4 in winter. GSMaP-V5 receives higher POD scores than GSMaP-V4 in summer. However, its FAR scores are worse than GSMaP-V4 in summer.

3.2. Evaluation of GSMaP Precipitation Estimates over the Contiguous Chinese Mainland. The GSMaP product has been compared to a gauge-based analysis of daily precipitation over the contiguous Chinese Mainland for the four-year period from 2003 to 2006. Figure 3 shows the spatial distribution based on CMA-GRA and the GSMaP products. The precipitation distribution over the Chinese Mainland is characterized by a southeast to northwest decrease in the mean intensity of daily gauge-based analysis data. Both of the GSMaP precipitation estimates (Figures 3(b) and 3(d)) depict spatial pattern well. However, there is obvious underestimation over southern and southeastern portions of China, where landfall of typhoons and annual migration of the monsoon (Mei$\mathrm{Yu}$ ) bring about abundant fresh water. The GSMaP products tend to underestimate the annual precipitation by about 1$3 \mathrm{~mm} /$ day in these regions. There is also slight overestimation in the northwestern arid and semiarid regions, where annual mean precipitation is very low. Although there is slight overestimation in northwestern arid and semiarid region, the relative error in these regions is greater than that in southeastern and wet regions. The spatial distributions of mean precipitation for two GSMaP products are similar. The GSMaP-V5 partly corrects underestimation from GSMaPV4 over southeastern China. The enhanced precipitation of GSMaP-V5 is notable for regions with complex topography (e.g., the Tian Shan Mountains, marked in Figure 3(d)), since an orographic rainfall classification scheme was involved in GSMaP product [27]. However, overestimation is also detected in these regions (Figure 3(e)).

Figure 4 shows the spatial distribution of ME GSMaP products on $0.25^{\circ}$ grid. MEs illustrate that GSMaP products overestimate precipitation over northwestern China and underestimate precipitation over southeastern China. The overestimation in GSMaP-V5 is slightly larger than in GSMaP-V4. GSMaP-V5 shows close spatial patterns and magnitudes of RMSE with GSMaP-V4 (Figure 5). Differences are notable over inland mountain regions with complex topography. GSMaP-V5 receives larger RMSE values than GSMaP-V4 in these regions (Figure 5(c)). The CCs of GSMaP products are good over most regions of the Chinese Mainland. Serial correlation coefficient reaches 0.7 or higher over southeastern China and less than 0.2 over most regions of northwest China (Figure 6). The most notable differences of CC between GSMaP-V4 and GSMaP-V5 are detected over northwestern China (Figure 6(c)). Spatial patterns of POD and FAR are shown in Figures 7 and 8. GSMaP products have a reasonably good POD, which ranges from 0.5 to 0.9 over most of China. The highest POD reached $90 \%$ in central China. FAR ranges from 0.1 to 0.7 . The lowest FAR is less than $10 \%$ in southeastern China. POD and FAR distributions of GSMaP-V5 agree quite well with GSMaP-V4.
TABLE 3: Validation statistics comparing the performances of GSMaP rainfall estimates over the Qinghai-Tibet Plateau (Region I).

\begin{tabular}{lcccccc}
\hline GSMaP version & Time & $\begin{array}{c}\text { Mean } \\
\text { mm/day }\end{array}$ & $\begin{array}{c}\text { ME } \\
\mathrm{mm} / \text { day }\end{array}$ & CC & POD & FAR \\
\hline \multirow{3}{*}{ V4 } & JJA & 3.03 & -0.16 & 0.60 & 0.85 & 0.22 \\
& DJF & 0.25 & 0.12 & 0.17 & 0.39 & 0.83 \\
& All year & 1.41 & 0.08 & 0.62 & 0.79 & 0.46 \\
V5 & JJA & 3.58 & 0.38 & 0.59 & 0.88 & 0.23 \\
& DJF & 1.02 & 0.89 & 0.14 & 0.48 & 0.83 \\
& All year & 1.90 & 0.57 & 0.47 & 0.83 & 0.47 \\
\hline
\end{tabular}

3.3. Evaluation of Regional GSMaP Precipitation Estimates. As shown in Section 3.2, the accuracy of the GSMaP products varies in different region over the Chinese Mainland. This phenomenon also appears in Colombia [13] and the United States [22]. Thus, a validation that uses data from the whole country may not present the entire picture of GSMaP in accuracy. In this section, the accuracy of GSMaP products from region to region will be explored. The Chinese Mainland is divided into three parts (Figure 1) for the purpose of calculating statistic variables. These three parts are the Qinghai-Tibet Plateau (Region I), northern China (Region II), the latitude of which is higher than $40^{\circ}$, and southeastern China (Region III). Environmental characteristics of the three subregions are quite different. The average altitude of Region I is above $3000 \mathrm{~m}$. And it has complex terrain and snow cover in its hinterland. Region II consists of areas at north of $40^{\circ} \mathrm{N}$, not covered by TRMM satellite. Region III is the wettest part of China. It is covered by TRMM satellite, with no snow cover or complex terrain. To compare the performances of GSMaP in different regions, we may discuss possible factors that impact the quality and error characteristics in GSMaP products.

Table 3 compares results for two GSMaP products over Region I. The mean daily precipitation is 1.41 and $1.90 \mathrm{~mm} /$ day for GSMaP-V4 and GSMaP-V5, respectively. There is no clear bias in GSMaP-V4, while obvious overestimation is found in GSMaP-V5. GSMaP-V4 underestimates precipitation about $0.16 \mathrm{~mm} /$ day in summer and overestimates $0.12 \mathrm{~mm} /$ day in winter. GSMaP-V5 largely overestimates precipitation both in winter and in summer. We guess that the overestimation is related to the orographic rainfall classification scheme used by GSMaP-V5. GSMaP-V4 also gets a better CC score than GSMaP-V5. However, POD score of GSMaP-V5 is higher than GSMaP-V4. FAR values of GSMaP-V5 are close to GSMaP-V4's values. All statistics indicate that the GSMaP performs better in summer than in winter in Region I.

Validation statistics of GSMaP-V4 and GSMaP-V5 over high latitude regions (Region II) are shown in Table 4. The mean daily precipitation is 1.06 and $1.26 \mathrm{~mm}$ /day for GSMaP-V4 and GSMaP-V5, respectively. Bias does not appear in both products in summer. GSMaP-V4 underestimates precipitation in winter. Overestimation is found in GSMaPV5 in winter and all the year round. Comparing to GSMaP$\mathrm{V} 4$, CCs of GSMaP-V5 fall from 0.27 to 0.03 in winter and 


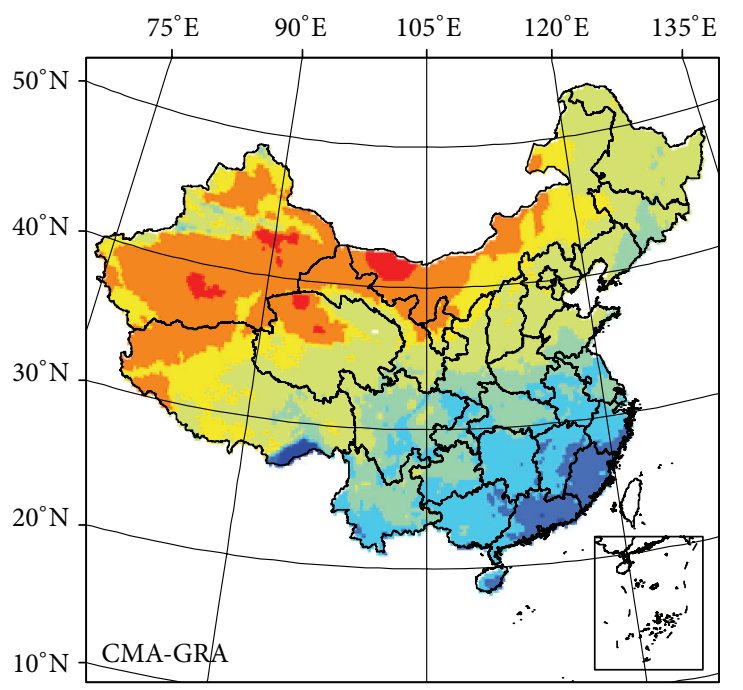

(a)

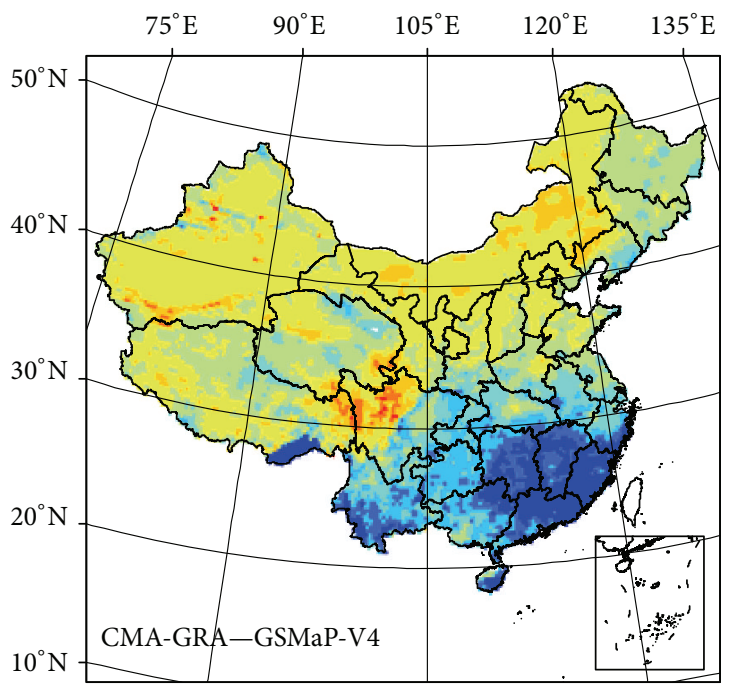

(c)

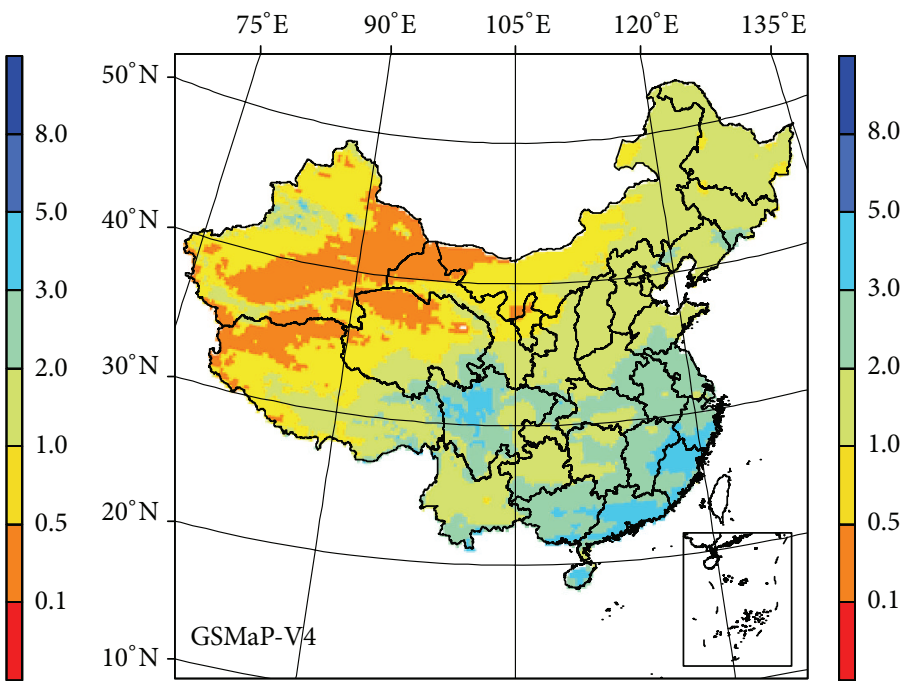

(b)

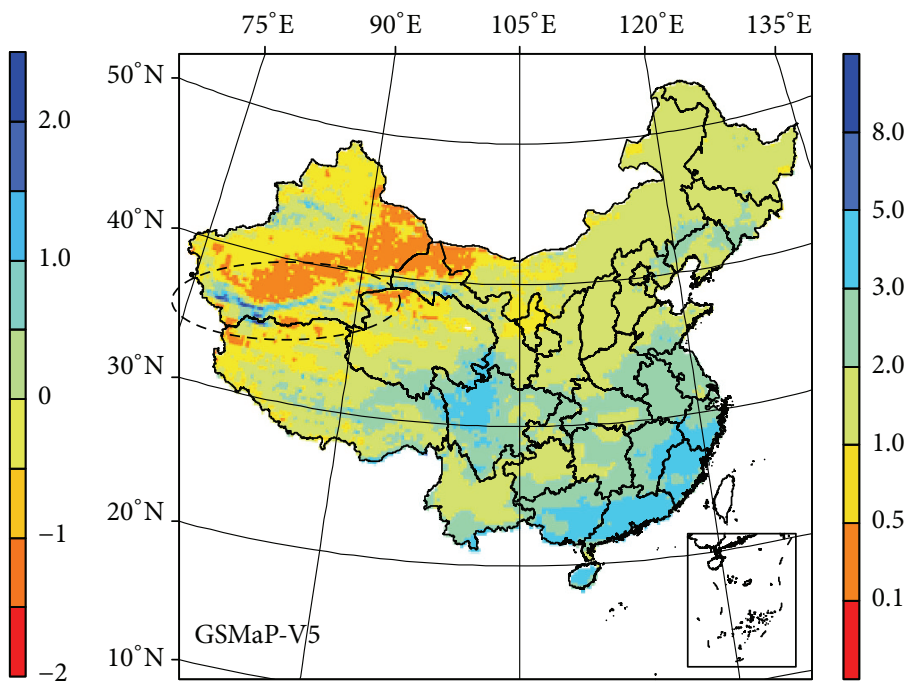

(d)

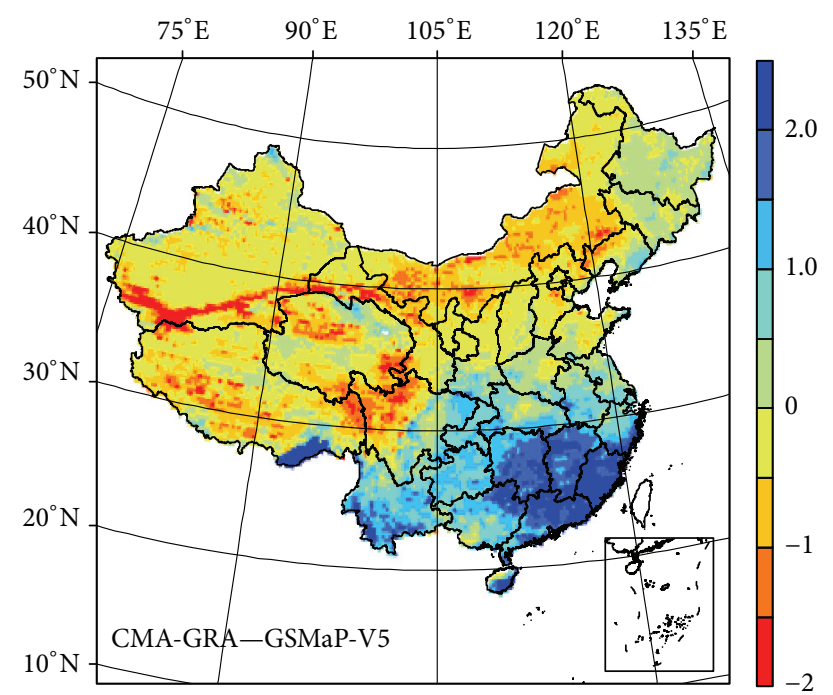

(e)

FIGURE 3: Distribution of daily mean precipitation over the Chinese Mainland from 2003 to 2006. Units are mm/day. (a) CMA-GRA, (b) GSMaP-V4, (c) differences between CMA-GRA and GSMaP-V4, (d) GSMaP-V5, and (e) differences between CMA-GRA and GSMaP-V5. 


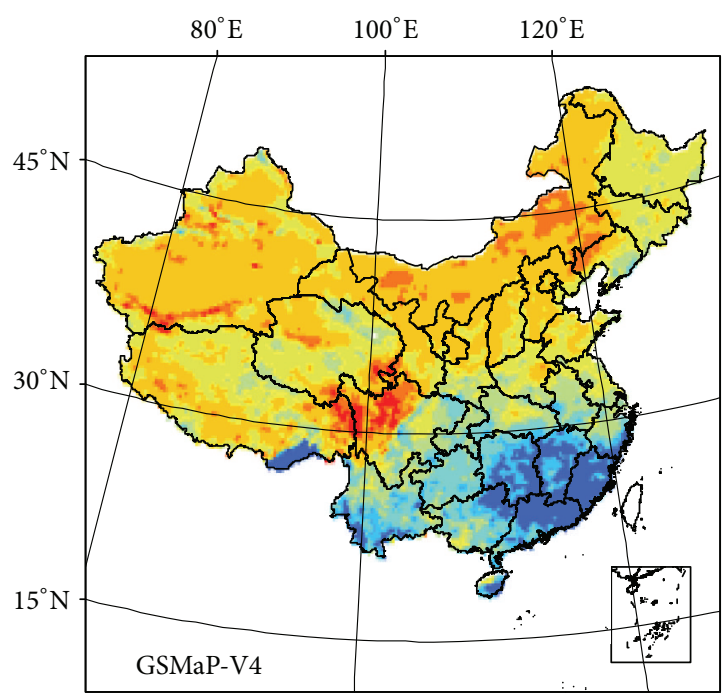

(a)
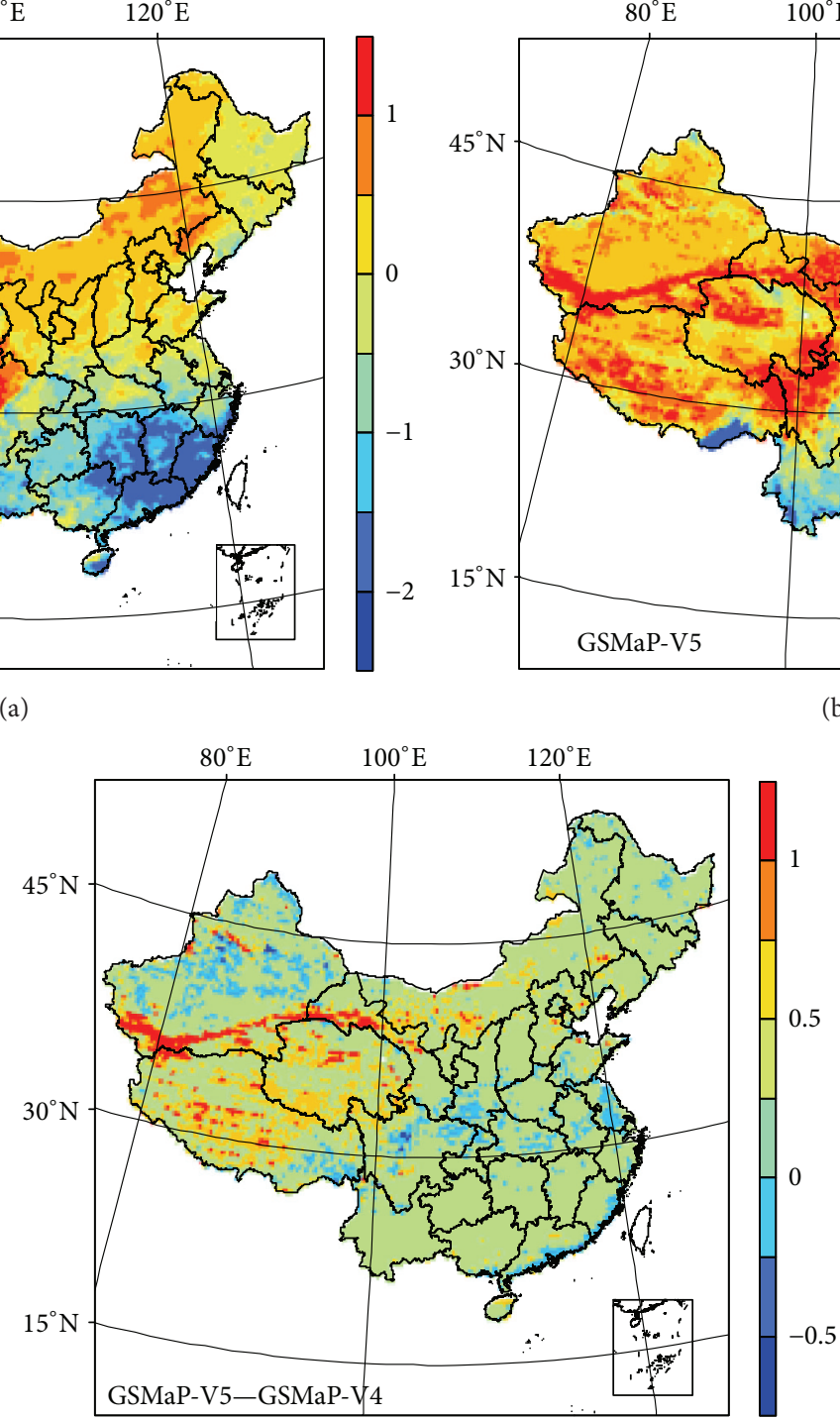

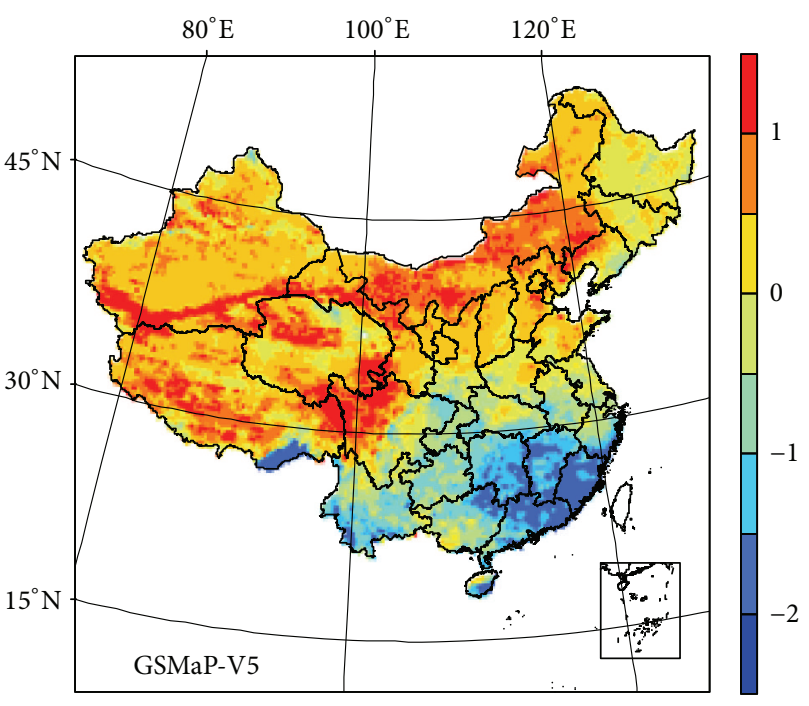

(b)

(c)

FIGURE 4: Distribution of mean errors for GSMaP products over the Chinese Mainland from 2003 to 2006. Units are mm/day. (a) GSMaP-V4, (b) GSMaP-V5, and (c) difference between GSMaP-V4 and GSMaP-V5.

TABLE 4: Validation statistics comparing the performances of GSMaP rainfall estimates over high latitude regions (Region II).

\begin{tabular}{lcccccc}
\hline \multirow{2}{*}{ GSMaP version } & Time & $\begin{array}{c}\text { Mean } \\
\text { mm/day }\end{array}$ & $\begin{array}{c}\text { ME } \\
\text { mm/day }\end{array}$ & CC & POD & FAR \\
\hline \multirow{4}{*}{ V4 } & JJA & 2.65 & -0.05 & 0.63 & 0.86 & 0.36 \\
& DJF & 0.05 & -0.14 & 0.27 & 0.08 & 0.72 \\
& All year & 1.06 & -0.02 & 0.64 & 0.65 & 0.46 \\
\hline \multirow{4}{*}{ V5 } & JJA & 2.76 & 0.06 & 0.61 & 0.89 & 0.37 \\
& DJF & 0.36 & 0.19 & 0.03 & 0.08 & 0.75 \\
& All year & 1.26 & 0.17 & 0.49 & 0.66 & 0.46 \\
\hline
\end{tabular}

from 0.64 to 0.49 all year round. POD and FAR scores of GSMaP-V5 are close to GSMaP-V4. GSMaP products also receive higher statistics values in summer than in winter.
Obvious underestimation is detected in both GSMaP products over Region III (Table 5). The underestimation shown in GSMaP-V4 is partly corrected in GSMaP-V5. ME reduces from -0.84 to -0.66 . Comparing to GSMaP-V4, CCs of GSMaP-V5 reduce from 0.61 to 0.25 in winter. Other statistics of GSMaP-V5 are close to GSMaP-V4's ones. The performances of GSMaP products in summer are still better than in winter in this region.

In summer, statistic variables of GSMaP products of three regions are similar. This indicates that complex terrain (Region I) and lack of TRMM coverage (Region II) may not lead to the declined quality of GSMaP in summer. But underestimation is usually found in this season. GSMaP products get the highest CC, POD, and FAR scores in summer over all three subregions. In winter, the performances of GSMaP products are quite different over the three subregions. 


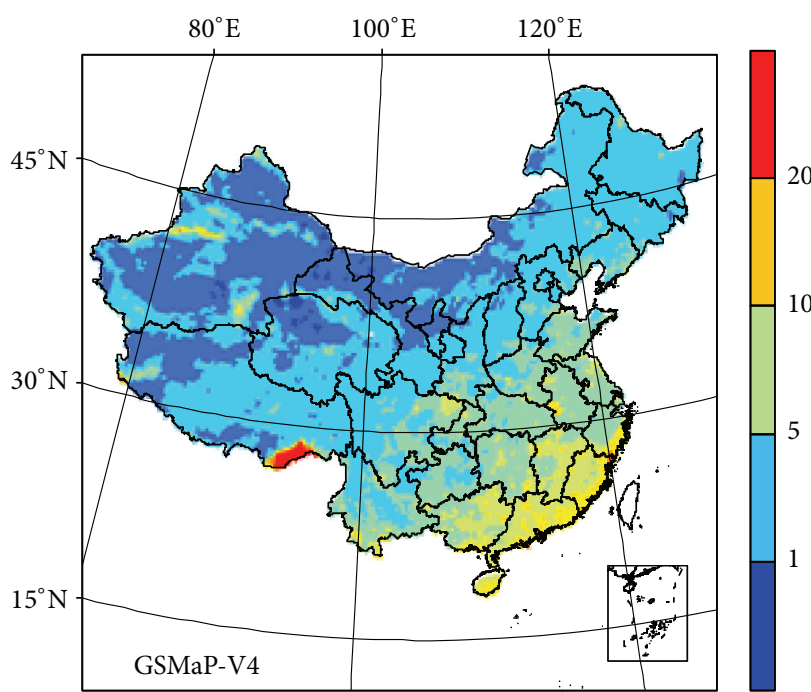

(a)

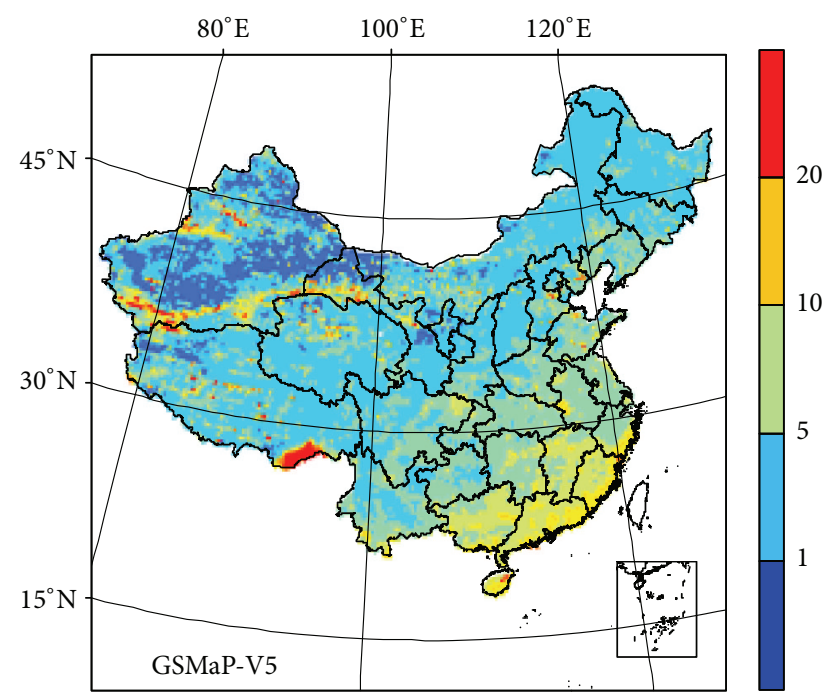

(b)

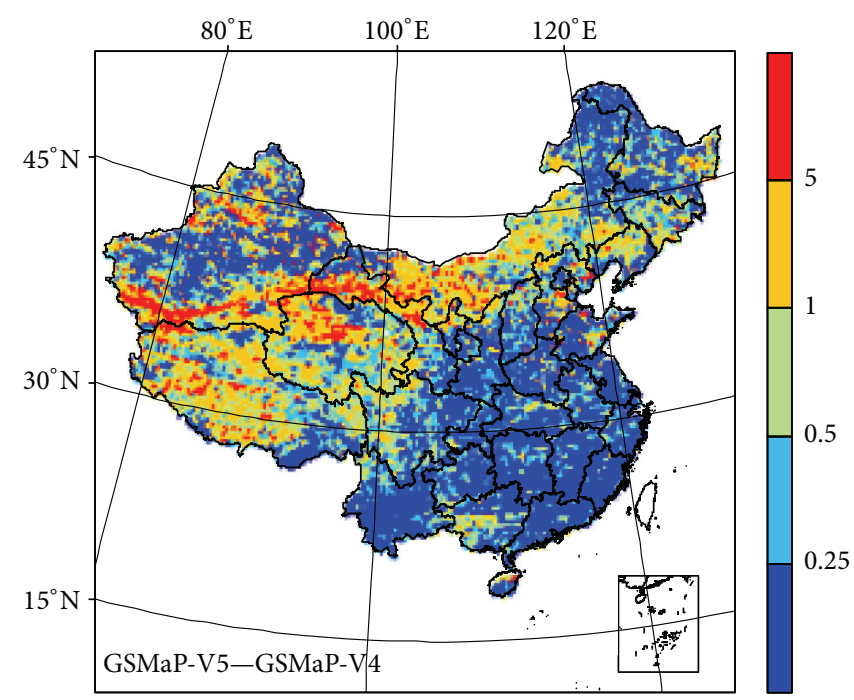

(c)

Figure 5: Distribution of root mean square errors for GSMaP products over the Chinese Mainland from 2003 to 2006. Units are mm/day. (a) GSMaP-V4, (b) GSMaP-V5, and (c) difference between GSMaP-V4 and GSMaP-V5.

TABLE 5: Validation statistics comparing the performances of GSMaP rainfall estimates over high latitude regions (Region III).

\begin{tabular}{lcccccc}
\hline \multirow{2}{*}{ GSMaP version } & Time & $\begin{array}{c}\text { Mean } \\
\text { mm/day }\end{array}$ & $\begin{array}{c}\text { ME } \\
\text { mm/day }\end{array}$ & CC & POD & FAR \\
\hline \multirow{4}{*}{ V4 } & JJA & 3.79 & -1.17 & 0.66 & 0.82 & 0.29 \\
& DJF & 0.33 & -0.60 & 0.61 & 0.38 & 0.48 \\
& All year & 1.84 & -0.84 & 0.67 & 0.69 & 0.34 \\
\hline \multirow{4}{*}{ V5 } & JJA & 4.24 & -0.72 & 0.64 & 0.87 & 0.33 \\
& DJF & 0.51 & -0.42 & 0.25 & 0.39 & 0.50 \\
& All year & 2.02 & -0.66 & 0.63 & 0.73 & 0.36 \\
\hline
\end{tabular}

The worst values of CC and POD are found in Region II in winter. We suggest that the declined accuracy of GSMaP products in this region is related to the lack of coverage by
TABLE 6: Mean NDVI and snow cover fraction over different regions in summer and winter.

\begin{tabular}{lcccc}
\hline & & Region III & Region II & Region I \\
\hline \multirow{2}{*}{ Summer (JJA) } & NDVI & 0.58 & 0.48 & 0.39 \\
& Snow cover & 0 & 0 & 0.01 \\
\hline \multirow{2}{*}{ Winter (DJF) } & NDVI & 0.33 & 0.2 & 0.11 \\
& Snow cover & 0.03 & 0.49 & 0.34 \\
\hline
\end{tabular}

TRMM satellite. In winter, snow cover fraction changed a little in Region III (Table 6). Comparing statistic variables of Region III in summer and winter can exclude the influence of snow cover. POD (FAR) changed from $0.82(0.29)$ to 0.38 (0.48) from summer to winter. It is hard to say the changes of POD and FAR are induced by snow cover in this region. 


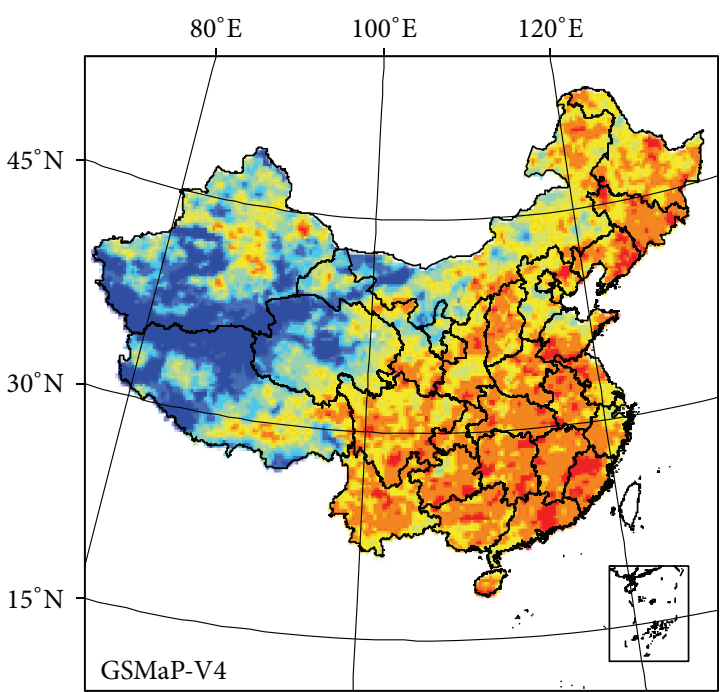

(a)

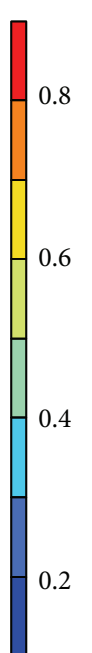

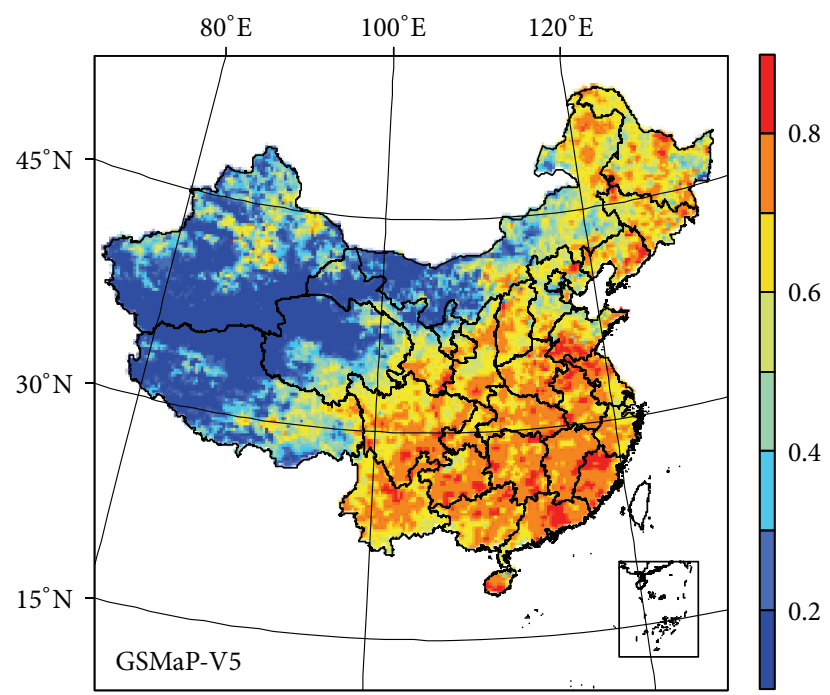

(b)

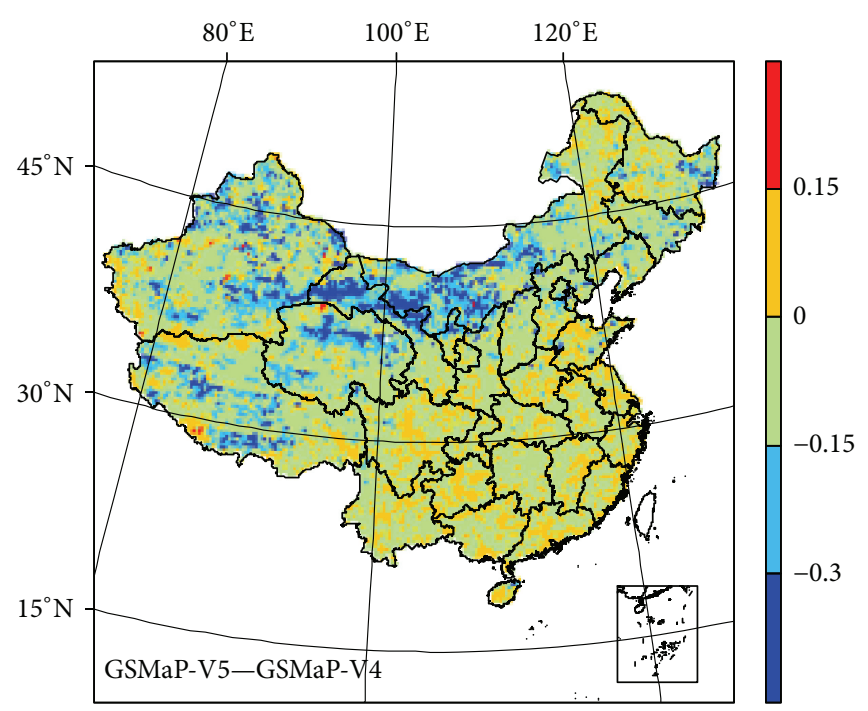

(c)

FIGURE 6: Distribution of correlation coefficient for GSMaP products over the Chinese Mainland from 2003 to 2006. (a) GSMaP-V4, (b) GSMaP-V5, and (c) difference between GSMaP-V4 and GSMaP-V5.

There are some other factors that influence the performance of GSMaP in different seasons over Region III. For example, the emission from winter precipitation is quite different from summer precipitation because of different temperature. Comparing statistic variables between Region I and Region III in winter, FAR changes from 0.83 to 0.48 and POD is slightly different (from 0.39 to 0.38 ). In winter, Region I, which has higher altitude, is covered by snow much larger than that in Region III (Table 6). This FAR change may be influenced by the snow cover.

3.4. Snow Cover Impacts on GSMaP Product. As it is mentioned above, GSMaP performs worse in winter than in summer over the Chinese Mainland. This situation is also detected in Tian et al.s [22] and Kubato et al.s [14] research.
Snow cover in winter may be a major factor that impacts the quality of GSMaP product. However, the relationship between snow cover and satellite-based precipitation estimates has rarely been discussed in previous study. In this study, we investigate the relationship between GSMaP's quality and daily snow cover fraction derived from MODIS daily snow data [36]. Snow cover fraction is a ratio covered by snow in every $0.05^{\circ}$ grid. As shown in Figure 9 (a), GSMaP-V4 underestimates precipitation in all snow cover fraction steps, while GSMaP-V5 overestimates precipitation. It shows that snow cover fraction does not impact bias of GSMaP products. But POD significantly decreased when snow cover fraction increased (Figure 9(b)). When there is no or little snow cover (snow cover fraction less than 10\%), POD is above 0.75 and POD decreases as snow cover increases. When snow cover reaches 90\%, POD is less than 0.4. In Figure 9(b), when snow 


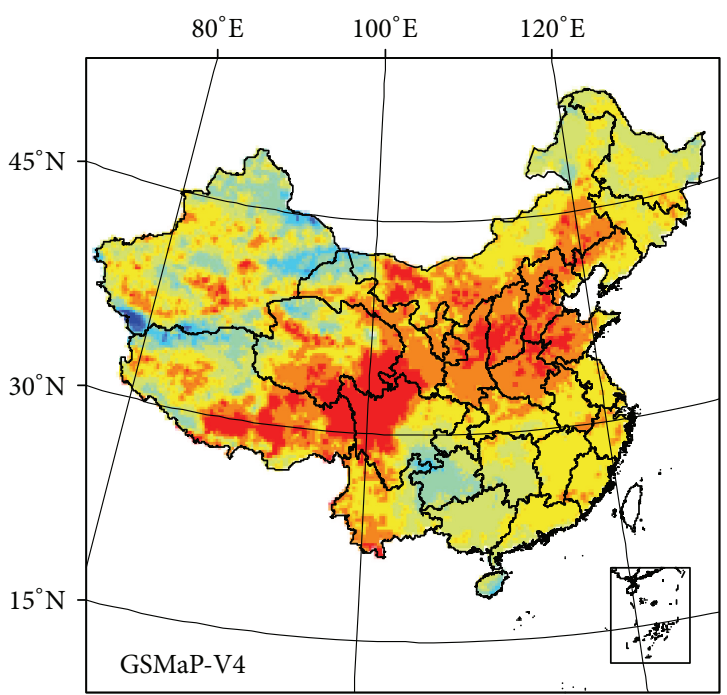

(a)
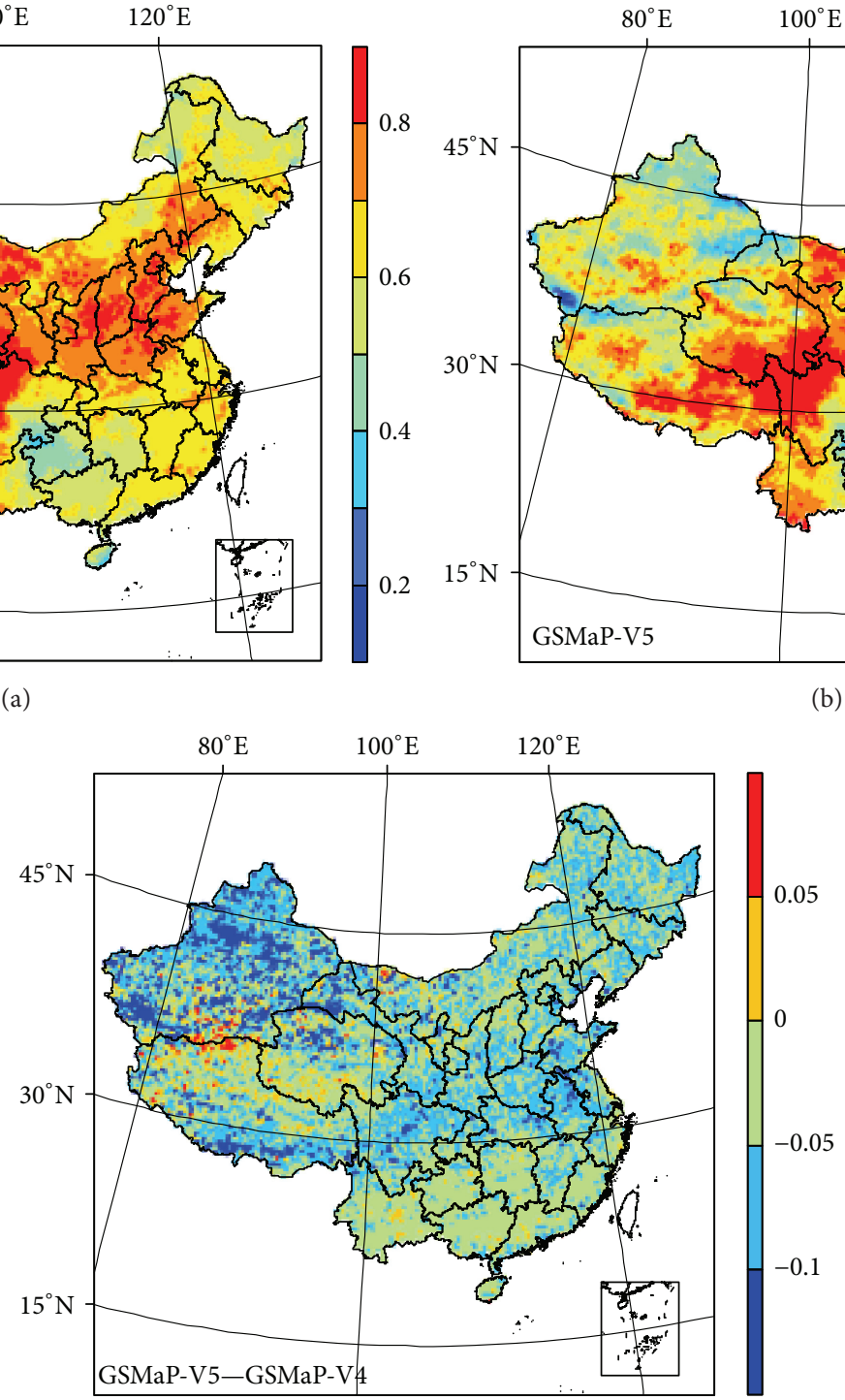

(c)

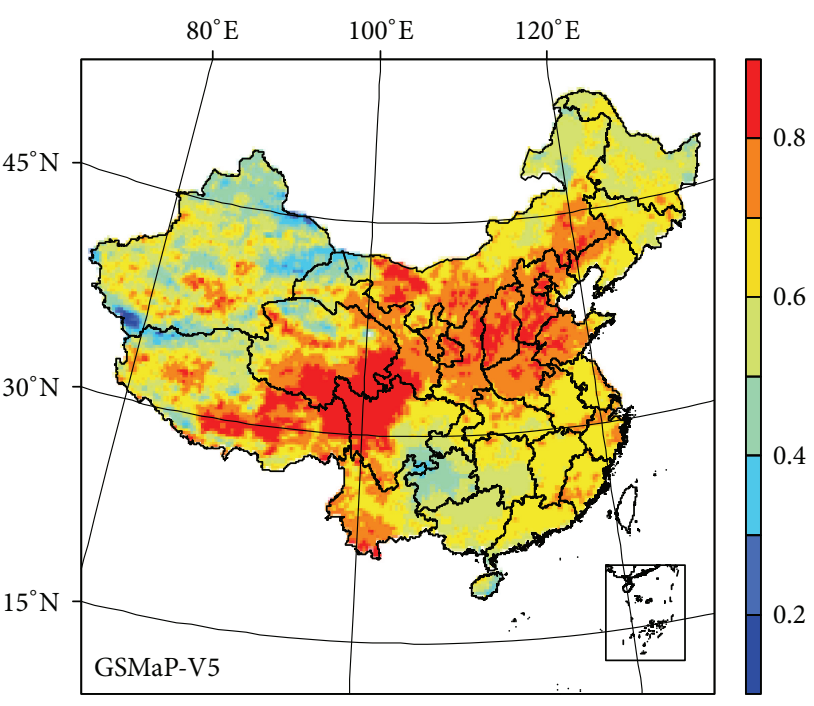

(b)

0.8 


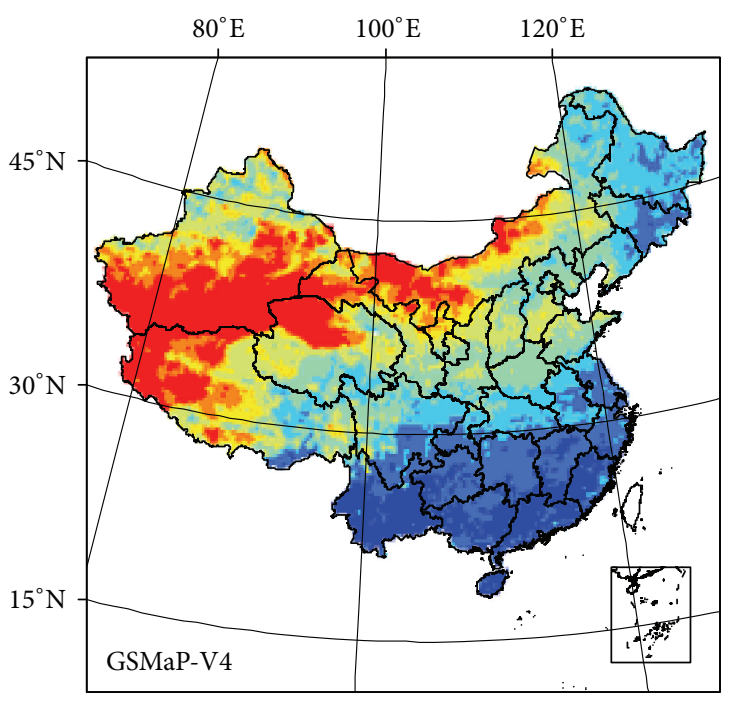

(a)
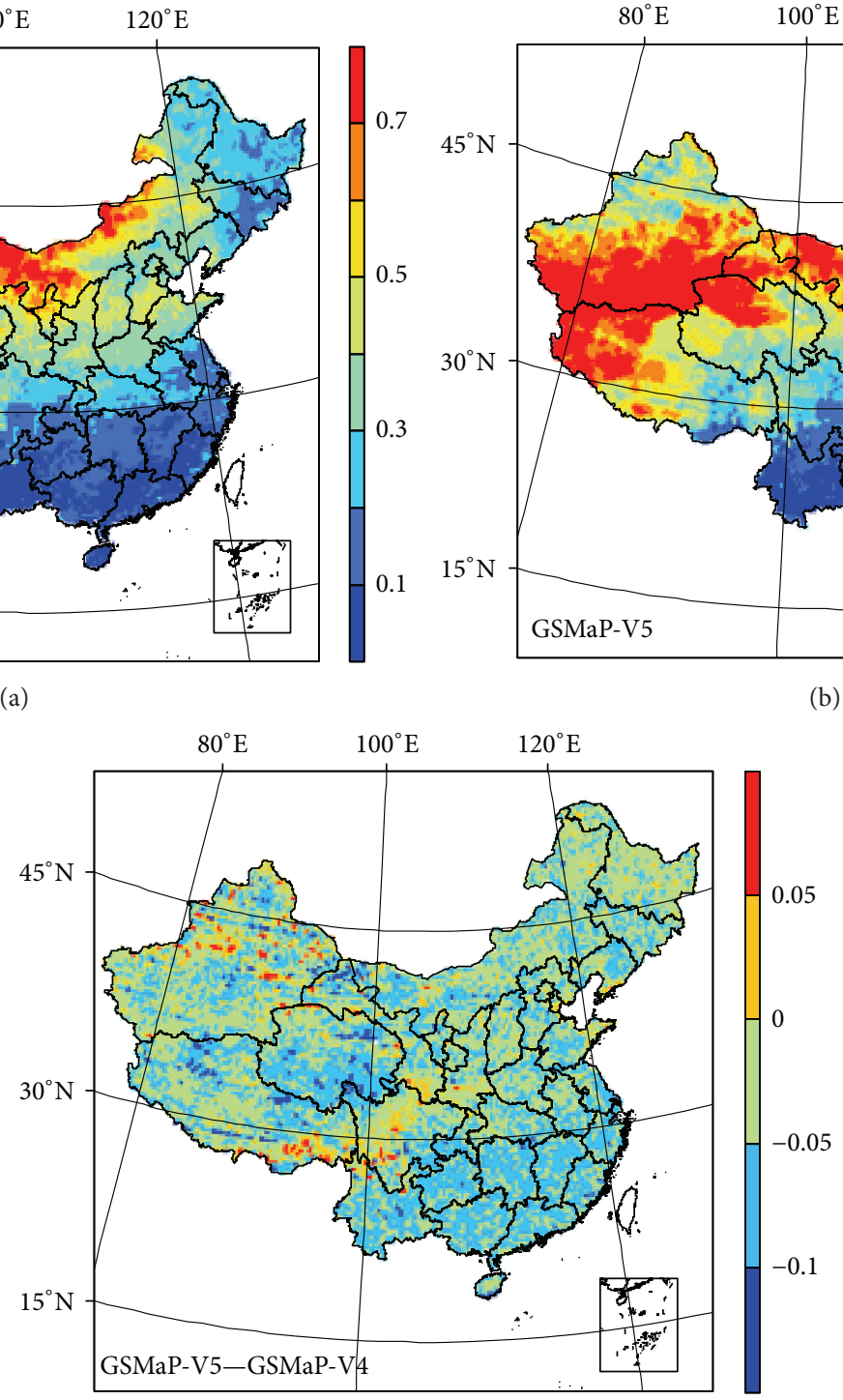

(c)

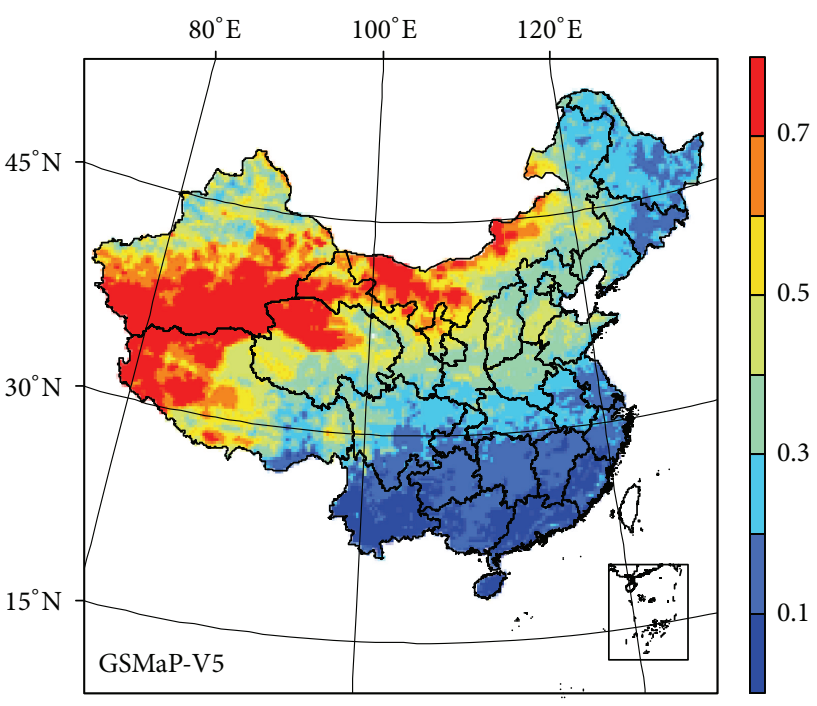

(b)
5

0.3

1

Figure 8: Distribution of false-alarm ratio for GSMaP products over the Chinese Mainland from 2003 to 2006. (a) GSMaP-V4, (b) GSMaP-V5, and (c) difference between GSMaP-V4 and GSMaP-V5.

high FAR may lead to overestimated precipitation of GSMaP in sparse vegetation region.

\section{Discussions}

Over the past decade, several global precipitation products based on multiple sensors have been extensively used in hydrological and meteorological applications [38, 39]. The Global Satellite Mapping of Precipitation (GSMaP) project is a recent addition to the repository of satellitebased high-resolution precipitation estimates. To facilitate the application of GSMaP and assess its improvement, it is crucial to quantify and document its error characteristics. In particular, Qin et al. [23] validated four precipitation datasets (CMORPH, GSMaP, TRMM-3B42, and TRMM3B42RT) over the Chinese Mainland. They found that GSMaP underestimated precipitation in most regions of China. Our result also supported this point well. But the new version GSMaP product (GSMaP-V5) partly corrected the underestimation. Many previous studies [40-42] indicated that complex topography may influence the accuracy of satellitebased precipitation estimates. Qin et al. [23] also suggested that it is necessary to investigate error characteristics in detail for popular satellite-based precipitation products over the Qinghai-Tibet Plateau with a very complex topography. Our results suggested that complex terrain (Region I) may not lead to the declined quality of GSMaP in summer. However, GSMaP products might miss the changes of precipitation caused by topographic changes in winter. Although the orographic rainfall classification scheme was involved in new version GSMaP product (GSMaP-V5), it seems that little improvements were found in new version GSMaP product. 


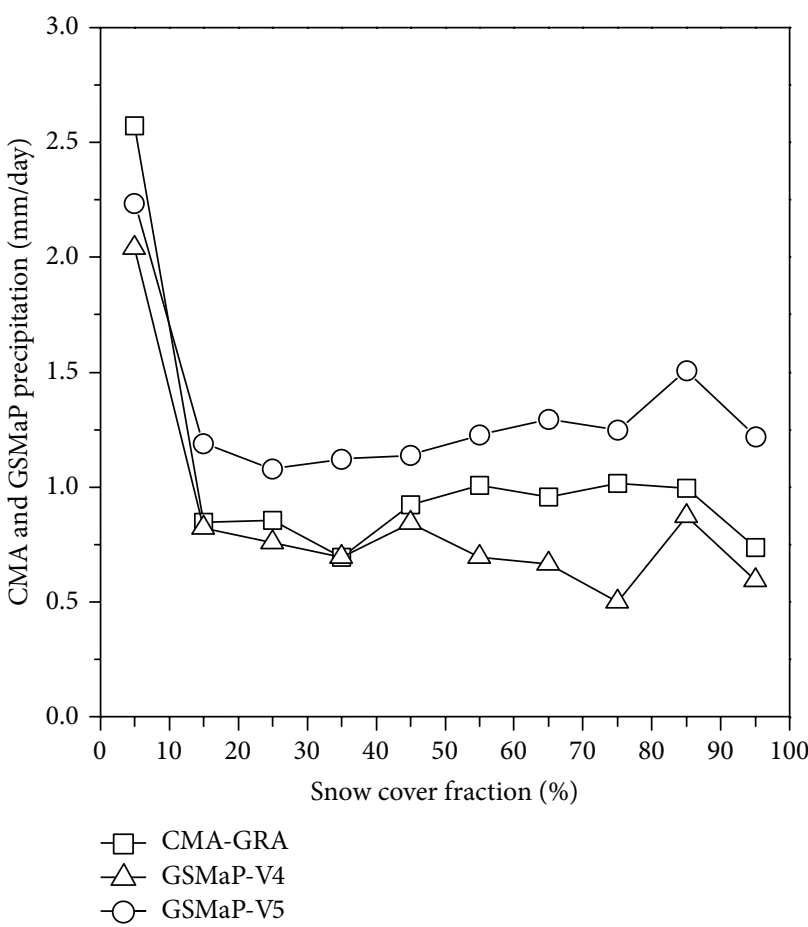

(a)

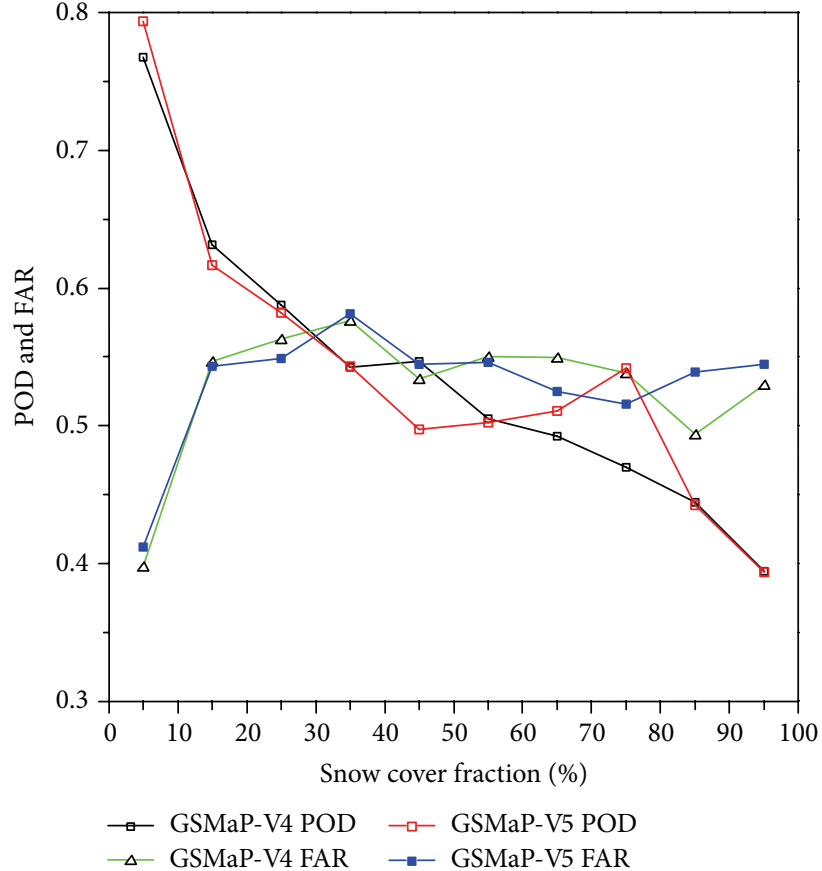

(b)

FIGURE 9: Relationship between statistics of GSMaP and snow cover fraction. (a) CMA and GSMaP precipitation amount. (b) POD and FAR.

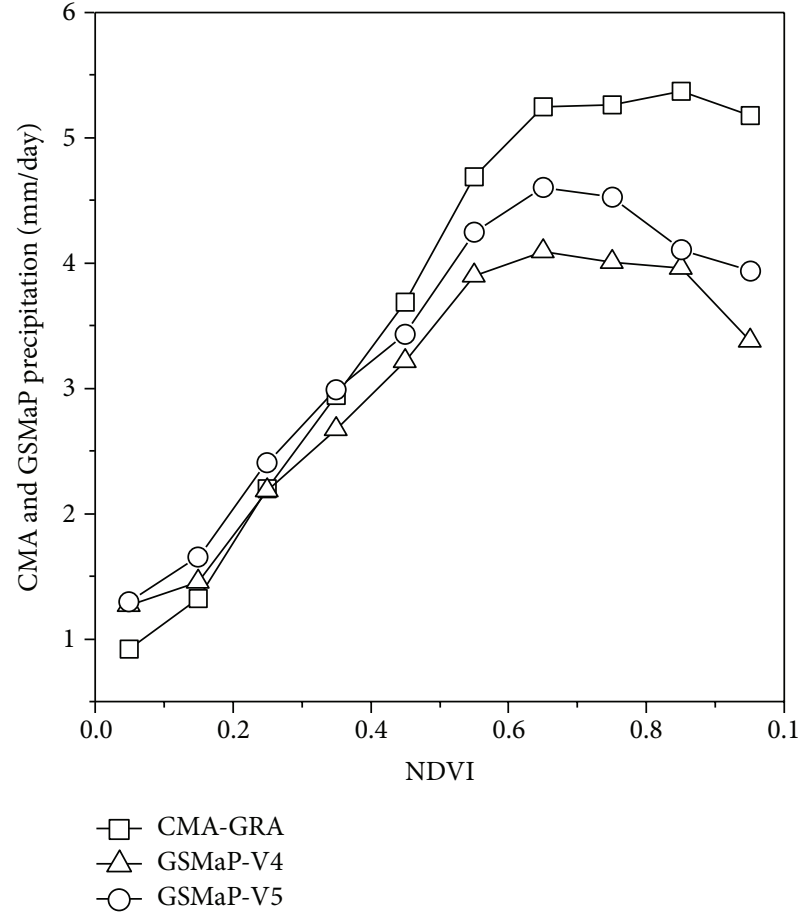

(a)

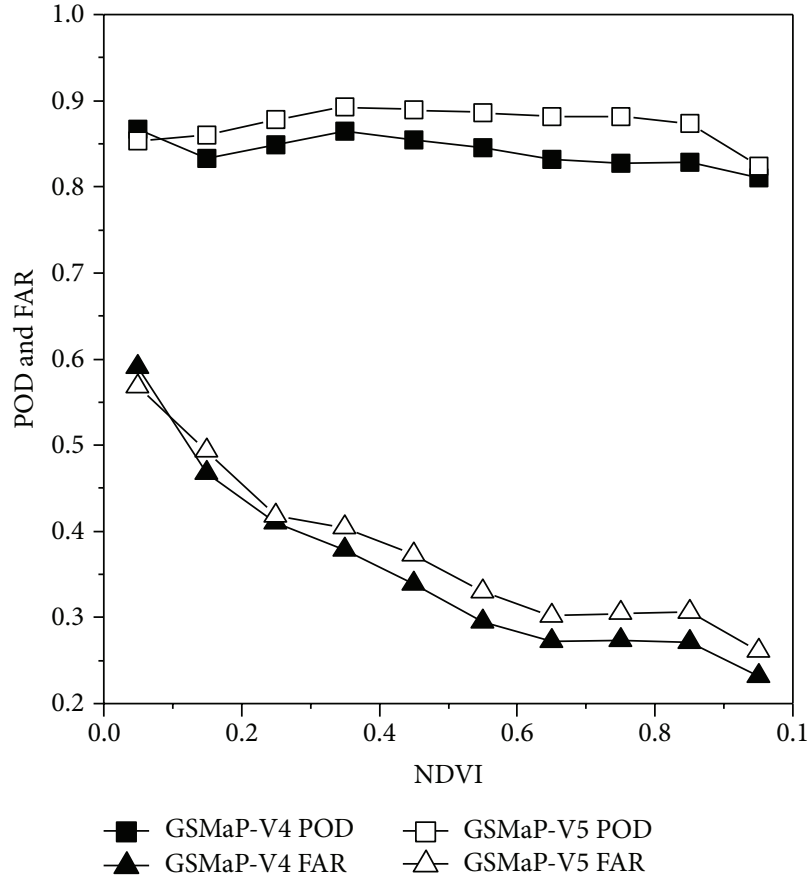

(b)

FIgUre 10: Relationship between statistics of GSMaP and NDVI. (a) CMA and GSMaP precipitation amount. (b) POD and FAR. 
Due to the sparse and irregular gauge network, it is difficult to provide effective evaluation of rainfall over the Qinghai-Tibet Plateau. It is necessary to evaluate satellite-based precipitation products using other data sources, such as precipitation radar.

Moreover, many previous studies illustrated that errors in satellite-based precipitation estimates are partly related to underlying surface types $[28,29]$. We also investigate errors of GSMaP products induced by snow cover and dense vegetation cover. Our result suggested that $\mathrm{POD}$ significantly decreased when snow cover fraction increased. NDVI does not have an impact on POD index. But FAR decreases when NDVI increases. However, snow cover or vegetation index may only partly represent the land surface conditions. There are many other factors that may influence the accuracy of GSMaP products, such as land cover types. Therefore, a more detailed description of errors characteristics is needed for satellite-based precipitation products.

\section{Conclusion}

GSMaP products (GSMaP-V4 and GSMaP-V5) have been evaluated by using a station network of about 2000 rain gauges and a gauge-based analysis of daily precipitation data over contiguous China during a four-year period from 2003 to 2006. Conclusions are as follows:

(1) GSMaP has performed very well over the Chinese Mainland. Systemic underestimation of about $0.53 \mathrm{~mm} /$ day is detected in GSMaP-V4. The underestimation existing in the GSMaP-V4 has been largely improved in GSMaP-V5. The correlation coefficient is 0.66 (0.6) for GSMaP-V4 (GSMaP-V5). POD and FAR of GSMaP-V4 (GSMaP-V5) are $0.70(0.73)$ and 0.38 (0.40), respectively.

(2) Both GSMaP products perform reasonably well in capturing seasonal variability in precipitation. They perform better in summer than in winter. The correlation coefficient is higher in summer than in winter. CC reaches 0.7 in summer and falls to below 0.4 in winter. POD and FAR show significant seasonal variation. In winter, the lowest POD is only $30 \%$, whereas the highest POD reaches nearly $80 \%$ in summer. The trend in values of FAR is opposite to those of POD.

(3) GSMaP products can capture spatial patterns and the magnitude of rainfall in daily mean precipitation. They tend to underestimate the annual precipitation over southern and southeastern China, while slightly overestimating over eastern Tibet and most of the northwestern arid and semiarid regions. CC, POD, and FAR also indicate that the performance of GSMaP over the southeastern or wet region is better than that over eastern Tibet and most of the northwestern arid and semiarid regions in China.

(4) GSMaP has been evaluated in three regions of China. In high altitude region (Region I), there is no clear bias in GSMaP-V4, while obvious overestimation is found in GSMaP-V5. In high latitude regions, bias does not appear in both products in summer. GSMaP$\mathrm{V} 4$ underestimates precipitation in winter, while overestimation is found in GSMaP-V5. In southeastern China, obvious underestimation is detected in both GSMaP products. In summer, other statistic variables of GSMaP products of three regions are similar. In winter, the performances of GSMaP products are quite different over the three subregions.

(5) Errors induced by land surface conditions are also explored in this study. Snow cover deeply impacts the POD and FAR of GSMaP product. But it seems there is no relationship between snow cover and bias of GSMaP products. GSMaP overestimates precipitation in sparse vegetation region (NDVI less than 0.2) and underestimates precipitation in dense vegetation region (NDVI larger than 0.4). FAR decreases when NDVI increases. POD remains a reasonable high value (about 0.85 ) in all NDVI thresholds.

\section{Conflict of Interests}

The authors declare that there is no conflict of interests regarding the publication of this paper.

\section{Acknowledgments}

The GSMaP project was sponsored by JST-CREST and promoted by the JAXA Precipitation Measuring Mission (PMM) Science Team, and the GSMaP products were distributed by the Earth Observation Research Center, Japan Aerospace Exploration Agency. This study was supported by the National Natural Science Foundation of China (Grant no. 41101375), Merging Technique Study of the Multisource Precipitation Data over China domain (GYHY201006042) of China Meteorological Administration, and the Fundamental Research Funds for the Central Universities (Grant no. 2013YB41).

\section{References}

[1] Y. Hong, R. F. Adler, A. Negri, and G. J. Huffman, "Flood and landslide applications of near real-time satellite rainfall products," Natural Hazards, vol. 43, no. 2, pp. 285-294, 2007.

[2] C. Kidd, V. Levizzani, J. Turk, and R. Ferraro, "Satellite precipitation measurements for water resource monitoring," Journal of the American Water Resources Association, vol. 45, no. 3, pp. 567-579, 2009.

[3] K.-L. Hsu, X. Gao, S. Sorooshian, and H. V. Gupta, "Precipitation estimation from remotely sensed information using artificial neural networks," Journal of Applied Meteorology, vol. 36, no. 9, pp. 1176-1190, 1997.

[4] G. J. Huffman, R. F. Adler, D. T. Bolvin, and E. J. Nelkin, "The TRMM multi-satellite precipitation analysis (TMPA)," Satellite Rainfall Applications for Surface Hydrology, pp. 3-22, 2010.

[5] R. J. Joyce and P. Xie, "Kalman filter-based CMORPH," Journal of Hydrometeorology, vol. 12, no. 6, pp. 1547-1563, 2011.

[6] T. Kubota, S. Shige, H. Hashizume et al., "Global precipitation map using satellite-borne microwave radiometers by the GSMaP project: production and validation," IEEE Transactions on Geoscience and Remote Sensing, vol. 45, no. 7, pp. 2259-2275, 2007. 
[7] R. F. Adler and A. J. Negri, "A satellite infrared technique to estimate tropical convective and stratiform rainfall," Journal of Applied Meteorology, vol. 27, no. 1, pp. 30-51, 1988.

[8] K. Aonashi, J. Awaka, M. Hirose et al., "GSMaP passive microwave precipitation retrieval algorithm: algorithm description and validation," Journal of the Meteorological Society of Japan. Ser. II, vol. 87, pp. 119-136, 2009.

[9] P. A. Arkin, R. Joyce, and J. E. Janowiak, "The estimation of global monthly mean rainfall using infrared satellite data: the GOES precipitation index (GPI)," Remote Sensing Reviews, vol. 11, no. 1-4, pp. 107-124, 1994.

[10] R. R. Ferraro, F. Weng, N. C. Grody et al., "NOAA operational hydrological products derived from the advanced microwave sounding unit," IEEE Transactions on Geoscience and Remote Sensing, vol. 43, no. 5, pp. 1036-1048, 2005.

[11] C. Kummerow, Y. Hong, W. S. Olson et al., "The evolution of the Goddard profiling algorithm (GPROF) for rainfall estimation from passive microwave sensors," Journal of Applied Meteorology, vol. 40, no. 11, pp. 1801-1820, 2001.

[12] E. E. Ebert, J. E. Janowiak, and C. Kidd, "Comparison of nearreal-time precipitation estimates from satellite observations and numerical models," Bulletin of the American Meteorological Society, vol. 88, no. 1, pp. 47-64, 2007.

[13] T. Dinku, F. Ruiz, S. J. Connor, and P. Ceccato, "Validation and intercomparison of satellite rainfall estimates over Colombia," Journal of Applied Meteorology and Climatology, vol. 49, no. 5, pp. 1004-1014, 2010.

[14] T. Kubota, T. Ushio, S. Shige, S. Kida, M. Kachi, and K. Okamoto, "Verification of high-resolution satellite-based rainfall estimates around Japan using a gauge-calibrated ground-radar dataset. 2. Global Satellite Mapping of Precipitation (GSMaP) Project," Journal of the Meteorological Society of Japan. Series II, vol. 87, pp. 203-222, 2009.

[15] J. Liu, Z. Duan, J. Jiang, and A. Zhu, "Evaluation of three satellite precipitation products TRMM 3B42, CMORPH, and PERSIANN over a subtropical watershed in China," Advances in Meteorology, vol. 2015, Article ID 151239, 13 pages, 2015.

[16] M. R. P. Sapiano, "An evaluation of high resolution precipitation products at low resolution," International Journal of Climatology, vol. 30, no. 9, pp. 1416-1422, 2010.

[17] M. L. Scheel, M. Rohrer, C. Huggel, D. S. Villar, E. Silvestre, and G. J. Huffman, "Evaluation of TRMM multi-satellite precipitation analysis (TMPA) performance in the Central Andes region and its dependency on spatial and temporal resolution," Hydrology and Earth System Sciences, vol. 15, no. 8, pp. 26492663, 2011.

[18] R. J. Joyce, J. E. Janowiak, P. A. Arkin, and P. Xie, "CMORPH: a method that produces global precipitation estimates from passive microwave and infrared data at high spatial and temporal resolution," Journal of Hydrometeorology, vol. 5, no. 3, pp. 487503, 2004.

[19] T. Ushio, K. Sasashige, T. Kubota et al., "A kalman filter approach to the global satellite mapping of precipitation (GSMaP) from combined passive microwave and infrared radiometric data," Journal of the Meteorological Society of Japan, vol. 87, pp. 137151, 2009.

[20] S. Seto, T. Kubota, T. Oki, N. Takahashi, and T. Iguchi, "Advanced rain/no-rain classification methods for microwave radiometer observations over land," Journal of Applied Meteorology and Climatology, vol. 47, no. 11, pp. 3016-3029, 2008.

[21] S. Seto, N. Takahashi, and T. Iguchi, "Rain/no-rain classification methods for microwave radiometer observations over land using statistical information for brightness temperatures under no-rain conditions," Journal of Applied Meteorology, vol. 44, no. 8, pp. 1243-1259, 2005.

[22] Y. Tian, C. D. Peters-Lidard, R. F. Adler, T. Kubota, and T. Ushio, "Evaluation of GSMaP precipitation estimates over the contiguous United States," Journal of Hydrometeorology, vol. 11, no. 2, pp. 566-574, 2010.

[23] Y. Qin, Z. Chen, Y. Shen, S. Zhang, and R. Shi, "Evaluation of satellite rainfall estimates over the Chinese Mainland," Remote Sensing, vol. 6, no. 11, pp. 11649-11672, 2014.

[24] Q. Hu, D. Yang, Z. Li, A. K. Mishra, Y. Wang, and H. Yang, "Multi-scale evaluation of six high-resolution satellite monthly rainfall estimates over a humid region in China with dense rain gauges," International Journal of Remote Sensing, vol. 35, no. 4, pp. 1272-1294, 2014.

[25] Q. Hu, D. Yang, Y. Wang, and H. Yang, "Accuracy and spatiotemporal variation of high resolution satellite rainfall estimate over the Ganjiang River Basin," Science China Technological Sciences, vol. 56, no. 4, pp. 853-865, 2013.

[26] M. Kachi, T. Kubota, K. Aonashi et al., "Recent improvements in the global satellite mapping of precipitation (GSMaP)," in Proceedings of the IEEE International Geoscience and Remote Sensing Symposium (IGARSS '14), pp. 3762-3765, Quebec City, Canada, July 2014.

[27] M. K. Yamamoto and S. Shige, "Implementation of an orographic/nonorographic rainfall classification scheme in the GSMaP algorithm for microwave radiometers," Atmospheric Research, vol. 163, pp. 36-47, 2015.

[28] A. S. Gebregiorgis and F. Hossain, "Understanding the dependence of satellite rainfall uncertainty on topography and climate for hydrologic model simulation," IEEE Transactions on Geoscience and Remote Sensing, vol. 51, no. 1, pp. 704-718, 2013.

[29] A. S. Gebregiorgis, Y. Tian, C. D. Peters-Lidard, and F. Hossain, "Tracing hydrologic model simulation error as a function of satellite rainfall estimation bias components and land use and land cover conditions," Water Resources Research, vol. 48, no. 11, Article ID W11509, 2012.

[30] Y. Shen, A. Xiong, and P. Xie, 7.3 Performance of HighResolution Satellite Precipitation Products over China, China Meteorological Administration, Beijing, China, 2010.

[31] P. Xie and A.-Y. Xiong, "A conceptual model for constructing high-resolution gauge-satellite merged precipitation analyses," Journal of Geophysical Research: Atmospheres, vol. 116, no. 21, Article ID D21106, 2011.

[32] M. Chen, W. Shi, P. Xie et al., "Assessing objective techniques for gauge-based analyses of global daily precipitation," Journal of Geophysical Research: Atmospheres, vol. 113, no. 4, Article ID D04110, 2008.

[33] P. Xie, A. Yatagai, M. Chen et al., "A gauge-based analysis of daily precipitation over East Asia," Journal of Hydrometeorology, vol. 8, no. 3, pp. 607-626, 2007.

[34] C. Daly, R. P. Neilson, and D. L. Phillips, "A statisticaltopographic model for mapping climatological precipitation over mountainous terrain," Journal of Applied Meteorology, vol. 33, no. 2, pp. 140-158, 1994.

[35] K. Okamoto, T. Ushio, T. Iguchi, N. Takahashi, and K. Iwanami, "The global satellite mapping of precipitation (GSMaP) project," in Proceedings of the IEEE International Geoscience and Remote Sensing Symposium (IGARSS '05), pp. 3414-3416, July 2005.

[36] D. K. Hall, G. A. Riggs, V. V. Salomonson, N. E. DiGirolamo, and K. J. Bayr, "MODIS snow-cover products," Remote Sensing of Environment, vol. 83, no. 1-2, pp. 181-194, 2002. 
[37] E. Ebert, "Methods for verifying satellite precipitation estimates," in Measuring Precipitation from Space, pp. 345-356, Springer, 2007.

[38] J. Gottschalck, J. Meng, M. Rodell, and P. Houser, "Analysis of multiple precipitation products and preliminary assessment of their impact on Global Land Data Assimilation System land surface states," Journal of Hydrometeorology, vol. 6, no. 5, pp. 573-598, 2005.

[39] Y. Tian, C. D. Peters-Lidard, B. J. Choudhury, and M. Garcia, "Multitemporal analysis of TRMM-based satellite precipitation products for land data assimilation applications," Journal of Hydrometeorology, vol. 8, no. 6, pp. 1165-1183, 2007.

[40] A. AghaKouchak, A. Behrangi, S. Sorooshian, K. Hsu, and E. Amitai, "Evaluation of satellite-retrieved extreme precipitation rates across the central United States," Journal of Geophysical Research-Atmospheres, vol. 116, Article ID D02115, 2011.

[41] C. Andermann, S. Bonnet, and R. Gloaguen, "Evaluation of precipitation data sets along the Himalayan front," Geochemistry, Geophysics, Geosystems, vol. 12, no. 7, Article ID Q07023, 2011.

[42] T. Dinku, S. Chidzambwa, P. Ceccato, S. J. Connor, and C. F. Ropelewski, "Validation of high-resolution satellite rainfall products over complex terrain," International Journal of Remote Sensing, vol. 29, no. 14, pp. 4097-4110, 2008. 

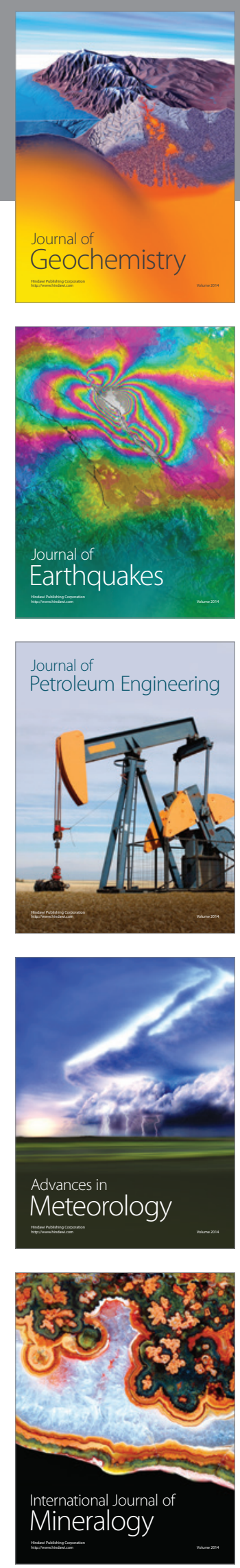
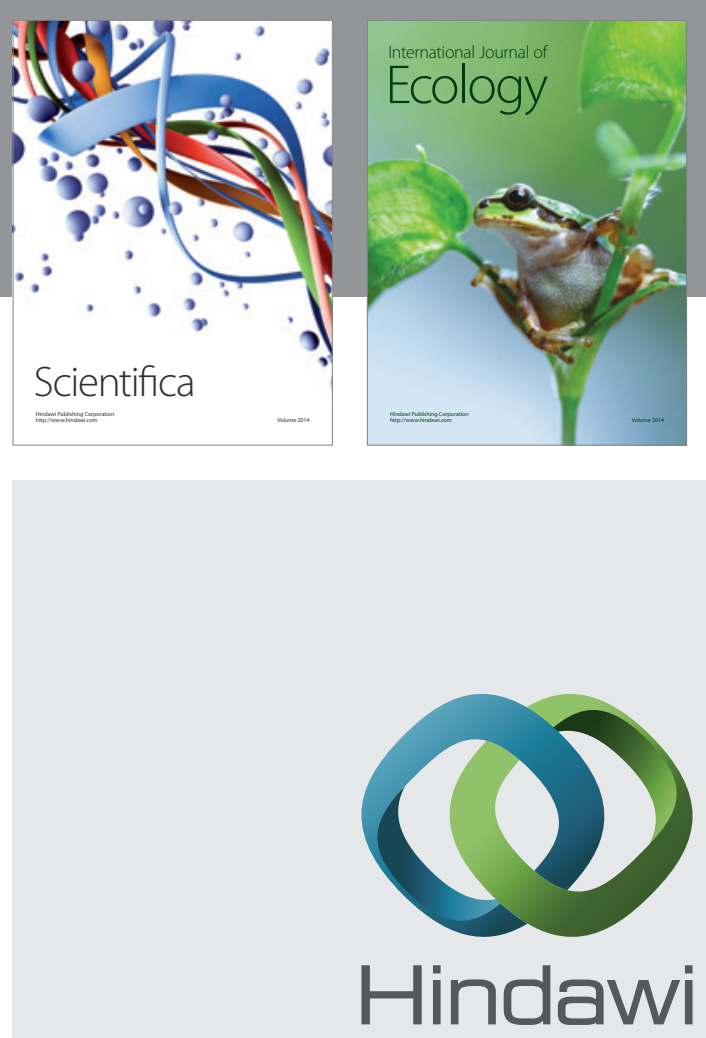

Submit your manuscripts at

http://www.hindawi.com
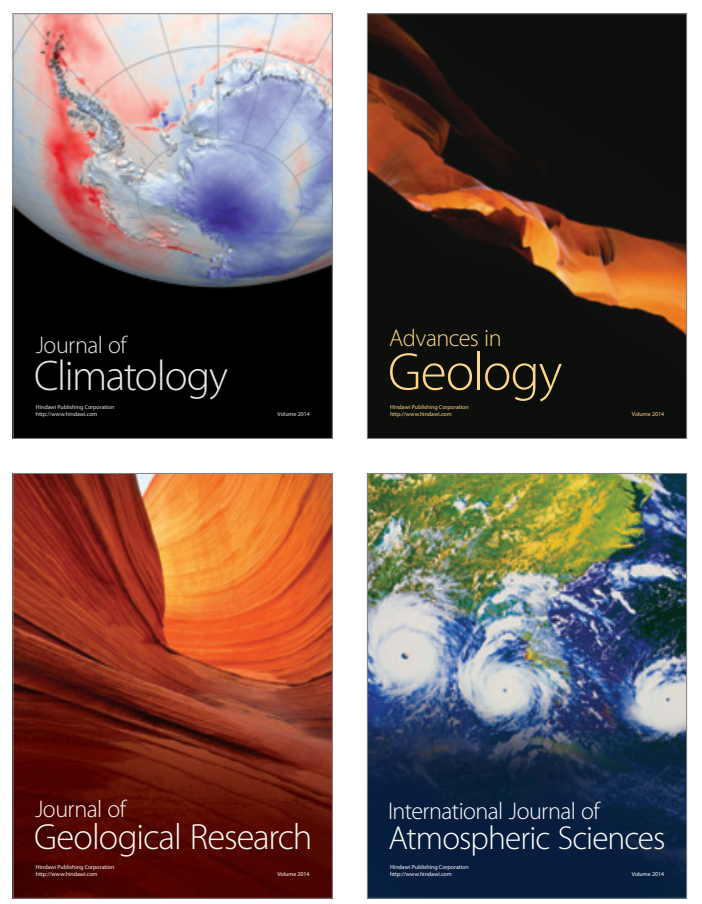

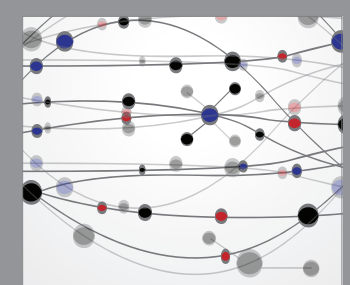

The Scientific

\section{World Journal}
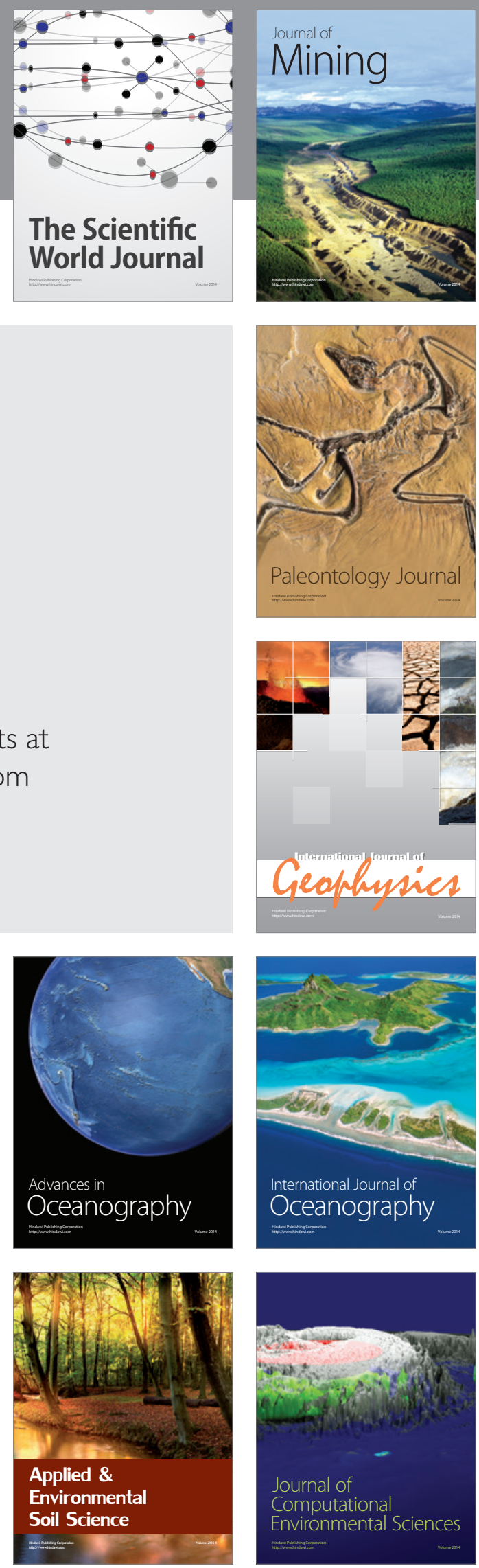